\title{
Silica applied as mixed matrix membrane inorganic filler for gas separation: a review
}

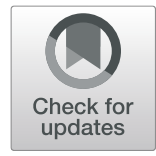

Wahyu Kamal Setiawan and Kung-Yuh Chiang*

\begin{abstract}
The trade-off relationship between gas permeability and selectivity is well-known as the primary barrier to developing polymeric membranes for the gas separation process. Mixed matrix membranes (MMMs) can be promoted as a solution to produce the desired membrane for gas separation processes. The general idea for synthesizing MMMs is to induce the thermal, electrical, mechanical, and molecular sieve properties of these nano materials into the base membrane. The incorporation of silica particles with molecular sieving properties in the polymer matrix is expected to lead to higher permeability and/or higher selectivity, compared to polymeric membranes. This paper reviews various types of silica incorporated into a polymer matrix and their gas transport mechanisms, MMM preparation methods and effect of silica on MMM characteristics and gas separation performance. MMM gas transport models after silica incorporation are also reviewed. In addition, the challenges and future works in developing MMMs with silica particles as inorganic filler are discussed.
\end{abstract}

Keywords: Mixed matrix membranes (MMMs), Silica, Inorganic fillers, Gas separation

\section{Introduction}

Membrane separation is promising to become an efficient and economical technique for gas separation applications. Membrane-based separation involves using a thin barrier between miscible fluids to separate a mixture. This interface may be molecularly homogeneous in which it is completely uniform in composition and structure, or it may be chemically or physically heterogeneous, in which pores or layered structures are formed. Polymeric membranes become a common practical material for many gas separation applications such as natural gas sweetening [1], petroleum refinery [2], landfill gas recovery [3], hydrogen recovery and purification, and flue gas separation [4]. This might due to their processability, mechanical strength, economic competitiveness and the scalability $[5,6]$. However, polymeric membranes still suffer a trade-off relationship between gas permeability and selectivity based on the Robeson's upperbound. Inorganic materials can be incorporated into polymeric membranes to overcome that limitation.

MMMs have experienced rapid growth over the past decade, overcoming the trade-off relationship among polymeric membranes. Other advantageous properties of

\footnotetext{
* Correspondence: kychiang@ncu.edu.tw

Graduate Institute of Environmental Engineering, National Central University, Taoyuan City 32001, Taiwan
}

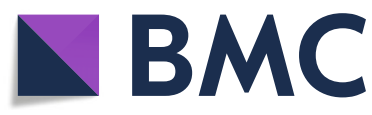

(c) The Author(s). 2019 Open Access This article is distributed under the terms of the Creative Commons Attribution 4.0 International License (http://creativecommons.org/licenses/by/4.0/), which permits unrestricted use, distribution, and

reproduction in any medium, provided you give appropriate credit to the original author(s) and the source, provide a link to the Creative Commons license, and indicate if changes were made. The Creative Commons Public Domain Dedication waiver (http://creativecommons.org/publicdomain/zero/1.0/) applies to the data made available in this article, unless otherwise stated.

MMMs include enhanced mechanical and thermal stability, reduced plasticization, lower energy requirement, and enhanced separation performance over native polymer membranes [7]. However, MMMs also still require some improvements before they can be commercialized, such as application of novel inorganic filler, development of permeation model with respect to intrinsic properties of filler, and employment of long-term stability test [8].

Generally, MMMs can be fabricated using two typical materials; polymer as the continuous phase and inorganic material as the dispersed phase. These two materials should be properly determined to achieve optimum performance from the resultant membranes. A polymer should be able to provide high chemical resistance, mechanical strength, and gas transport properties. Glassy polymers are preferable because they can provide better transport performance for typical gas mixtures compared to rubbery polymers [9]. On the other hand, inorganic materials create a preferential permeation pathway for selective permeability by posing as a barrier for unexpected permeation occasions. Several kinds of conventional inorganic materials have been used to develop MMMs such as zeolite, carbon molecular sieve, silica, and metal oxide.

Silica is an inorganic filler that has received prominent attention throughout MMM development. Silica 
particles can be classified into several types with regard to its pore and particle size. Each type of silica provides a distinct effect for the physical, chemical, and gas transport mechanism of a typical polymeric membrane. In general, the porous inorganic filler presents a molecular sieve, separating gases by their size or shape, with the result that high gas permeability and desired component selectivity are achieved. A non-porous inorganic filler diminishes the diffusion of larger molecules and enhances the matrix tortuous pattern [10]. Mesoporous materials exhibit large pores that have the ability to penetrate the polymer chain, producing better wetting and dispersion [11]. The presence of nano-sized inorganic materials may alter the polymer packing chain by increasing the void volume.

Silica incorporation into a glassy polymer is often applied to disrupt the trade-off relationship between gas permeability and selectivity. A glassy polymer poses distinct textural characteristics, creating synergetic performance with the inorganic filler to separate certain gas mixtures by tailoring free volume cavities. Many studies have been carried out to combine different glassy polymer properties with several types of silica particles such as the combination between high chain packing density glassy polymer with nano-sized silica particles [12-17], high density glassy polymers with fumed silica particles [5, 18-25], hyperbranched glassy polymer with nano-sized silica particles [26-28], crosslinked glassy polymer with fumed silica particles [29], high density glassy polymers with mesoporous silica particles $[9,11,30-36]$, hyperbranched glassy polymer with hollow silica microspheres [37], sulfonated glassy polymer with silica microspheres [38], glassy polymer with siloxane-type silica particles [39-42], and hyperbranched glassy polymer with mesoporous silica [43].
In gas mixture separation case, both the silica and polymer should be selected properly to adjust the morphology, textural characteristics, and gas transport properties. Silica can naturally change the polymer chain packing by rearranging the chain packing order. When the pore distance is controlled, the gas permeability and selectivity will be compromised.

This study aims to describe the recent developments in silica as inorganic filler in MMMs; differentiate the distinct silica particle mechanism that changes the morphology, textural characteristics, and polymer gas transport properties; and specify the ability of each type of silica particle to disrupt the trade-off relationship between gas permeability and selectivity.

\section{Various types of silica incorporated in polymer matrix and their gas transport mechanisms Non-porous, microporous, and mesoporous silica for MMMs preparation}

Fumed silica should be considered as the major nonporous silica applied for MMM fabrication. Some global producers provide various types of fumed silica with different commercial names such as Cabosil (Cabot Corporation, Boson, USA) and Aerosil (Evonik, Essen, Germany). They are produced using chlorosilane hydrolysis in an oxygenhydrogen gas flame, resulting in a three-dimensional structure with low bulk density and high surface area. Typically, fumed silica provides $5 \mathrm{~nm}-60 \mu \mathrm{m}$ of particle size, $45-430$ $\mathrm{m}^{2} \mathrm{~g}^{-1}$ of specific surface area, and $2.20-2.81 \mathrm{~g} \mathrm{~cm}^{-3}$ of density (Table 1). Due to their large surface area and the presence of numerous silanol groups on their surfaces, fumed silica exhibits higher hydrophilicity and higher surface energy. Therefore, it can be incorporated into various polymers such as glassy polymers, rubbery polymers, and

Table 1 Non-porous silica for mixed matrix membranes (MMMs) fabrication

\begin{tabular}{|c|c|c|c|c|c|}
\hline Commercial name & Surface area $\left(\mathrm{m}^{2} \mathrm{~g}^{-1}\right)$ & Particle size $(\mathrm{nm})$ & Density $\left(\mathrm{g} \mathrm{cm}^{-3}\right)$ & Incorporated polymer & Ref \\
\hline Cabosil TS 530*) & $205-245$ & $11.1-13.3$ & 2.2 & PIM-1 & [19] \\
\hline Aerosil R106 & - & 7 & - & PSf & {$[25]$} \\
\hline Aerosil R202 & $80-120$ & $5-50$ & - & PDMS & [23] \\
\hline Aerosil & - & $6 ; 17$ & - & PEBAX & [18] \\
\hline Aerosil & $45-55$ & 40 & - & PEBAX & {$[20]$} \\
\hline Fumed silica & 200 & 20 & - & PDMS & {$[21]$} \\
\hline Fumed silica & 390 & 7 & - & PVDF, P84 co-polyimide & {$[5,24]$} \\
\hline Fumed silica & $340-430$ & 7 & - & PVA & {$[29]$} \\
\hline Fumed silica & 200 & - & 2.2 & $\mathrm{PU}$ & [44] \\
\hline Fumed silica & - & 7 & 2.81 & PEBAX & {$[14,45]$} \\
\hline Fumed silica & 200 & 8 & 2.2 & PU & {$[46]$} \\
\hline Fumed silica & 412 & $40-60\left(10^{3}\right)$ & - & PVDF & {$[47]$} \\
\hline
\end{tabular}

PIM-1 soluble type of polymers of intrinsic microporosity, PSf polysulfone, PDMS polydimethylsiloxane, PEI polyethyleneimine, PVA polyvinyl alcohol, PU polyurethane, $P E B A X$ polyether block amide, PVDF polyvinylidene fluoride, $P 84$ co-polyimide BTDA-TDI/MDI co-polyimide, (-) not mentioned 
block copolymers with two segments. Higher free volume of MMMs would be expected when the fumed silica is applied into glassy polymer such as soluble type of polymers of intrinsic microporosity [19], polysulfone [25], polyvinylidene fluoride [5, 47], P84 co-polyimide [24], and polyvinyl alcohol [29]. Similarly, this filler is also desired to enhance free volume and matrix tortuous pattern in block copolymers such as polyether block amide [14, 18, 20], and polyurethane [44, 46]. In addition, good matrixfiller interactions and uniform filler dispersion can be achieved by applying fumed silica into rubbery polymers with compatible functional groups as well as siloxane groups in polydimethylsiloxane [23].

Mesoporous silica is identified by the presence of pores and pore size in the $2-50 \mathrm{~nm}$ range. SBA-15 (Santa Barbara Amorphous No. 15) is one mesoporous silica applied as inorganic filler in MMMs. SBA-15 can be synthesized using the hydrolysis-condensation hydrothermal reaction [48]. MCM-41 (Mobil Composition of Matter No. 41) is a commonly ordered mesoporous silica for MMM applications. Its hierarchical structure is made from silicate or aluminosilicate groups, using cylindrical mesopores that form a one-dimensional pore system. MCM-41 provides pore size in the $2-6 \mathrm{~nm}$ range, sharp pore distribution, and larger surface area compared to zeolites [45]. As can be seen in Table 2, MCM-41 is synthesized using hydrothermal $[5,11]$ or hydrolysis via a silica precursor sol-gel process such as sodium metasilicate [9], tetraethyl orthosilicate [5, 30-32, 36, 43], rice straw [13], and rice husk ash [35]. Surfactant molecules such as cetyltrimethylammonium bromide used as a template while ethyl acetate $\left(\mathrm{CH}_{3} \mathrm{COOC}_{2} \mathrm{H}_{5}\right)$ serves as an initiator for particle formation. The ordered mesoporous silica is frequently incorporated into glassy polymers such as polyphenylene oxide [48], polyvinylidene fluoride [5], polyimide [9, 31], hyperbranched hexafluoroisopropylidene [30], and polysulfone $[32,35]$. The results from those combinations are the significant improvement in gas selectivity due to mesopore structure and high surface area of MCM-41 or SBA-15. Mesoporous silica is also applied into polyethyleneimine [36] or polyether block amide [13] to fabricate MMMs due to their compatibility with silica hydrophobicity.

Microporous silica for MMM fabrication is found in the silica sol form using the Stöber method. This method is facilitated by hydrolysis and condensation of silica precursors in absolute methanol or ethanol with a base or acid catalyst. The common silica precursors are tetraethyl orthosilicate and tetramethyl orthosilicate. The base catalyst is ammonium hydroxide, while hydrochloric acid is used as the acid catalyst. Silica precursors should be hydrolysed using continuous stirring to form a clear and transparent silica sol. As shown in Table 3, the synthesized microporous silica is frequently applied into glassy polymers such as polyamide [27], polybenzimidazole [17], polysulfone/polyimide [16], and polyphenylene oxide [49] offering an approach similar to that of non-porous and mesoporous silica. The eminence of this filler should be good interconnectivity between the two-phase materials of the resultant MMMs. Moreover, microporous silica can also arrange the proportion between amorphous phase and crystalline phase into two polymer segments such as polyurethane [50, 51]. This arrangement is expected to balance the permeability and selectivity of gas permeates. Polymers with an additional functional group branch such as fluorinated polyimide [52], 6FpDA-DABA hyperbranched hexafluoroisopropylidene [26], and sulfonated polyether ether ketone [38] provide high compatibility with the micro porous silica hydrophilic site.

\section{Interfacial interaction of silica and polymer matrix}

Silica particles provide interfacial interaction or reaction as inorganic filler when applied to a polymer matrix. Recent investigations denoted that two interaction mechanisms occur with hydrogen bonding [49] and interfacial linking

Table 2 Mesoporous silica for mixed matrix membranes (MMMs) fabrication

\begin{tabular}{|c|c|c|c|c|c|c|c|}
\hline Mesoporous silica & Silica precursor & Synthesis method & Surface area $\left(\mathrm{m}^{2} \mathrm{~g}^{-1}\right)$ & Pore size $(\mathrm{nm})$ & Particle size $(\mathrm{nm})$ & Incorporated polymer & Ref \\
\hline SBA-15 & Tetraethyl orthosilicate & Hydrothermal & 411 & 4.6 & - & PPO & [48] \\
\hline \multirow[t]{9}{*}{ MCM-41 } & Sodium metasilicate & Sol gel & 851 & 2.7 & - & $\mathrm{PI}$ & {$[9]$} \\
\hline & Tetraethyl orthosilicate & Hydrothermal & 870 & 3.3 & - & $P E$ & [11] \\
\hline & & & 817 & 2.7 & 56 & PVDF & {$[5]$} \\
\hline & & Sol gel & 721 & 2.8 & 440 & 6FDA-4MPD-DABA & {$[30]$} \\
\hline & & & 889 & 2.5 & $100-150$ & PSf & [32] \\
\hline & & & 889 & 2.5 & $100-150$ & $\mathrm{Pl}$ & [31] \\
\hline & & & 915 & 2.7 & $100-150$ & PEl & [36] \\
\hline & Rice straw & Sol gel & 404 & 5.0 & $2-22$ & PEBAX & [13] \\
\hline & Rice husk ash & Sol gel & 295 & 15.35 & - & PSf & {$[35]$} \\
\hline
\end{tabular}


Table 3 Synthesized microporous silica for mixed matrix membranes (MMMs)

\begin{tabular}{|c|c|c|c|c|c|c|}
\hline$\underline{\text { Silica precursor }}$ & Chemical reagent & Surface area $\left(\mathrm{m}^{2} \mathrm{~g}^{-1}\right)$ & Pore size $(\mathrm{nm})$ & Particle size $(\mathrm{nm})$ & Incorporated polymer & Ref \\
\hline Tetramethyl orthosilicate & Dimethylacetamide & - & - & - & PA & {$[27]$} \\
\hline \multirow[t]{7}{*}{ Tetraethyl orthosilicate } & Hydrochloric acid, ethanol & - & - & - & $\mathrm{PBI}$ & {$[17]$} \\
\hline & & - & - & - & PSf/PI & [16] \\
\hline & & 577.29 & 2.2 & 2 & PPO & [49] \\
\hline & & & & & PU & {$[50,51]$} \\
\hline & 2,2,4-Trimethyl pentane & - & - & 9.4 & $\mathrm{FPI}$ & {$[52]$} \\
\hline & Ammonium hydroxide, ethanol & - & - & 45 & 6FDA-6FpDA-DABA & {$[26]$} \\
\hline & & 118.2 & & 180 & SPEEK & {$[38]$} \\
\hline
\end{tabular}

$P A$ polyamide, $P B I$ polybenzimidazole, $P S f$ polysulfone, $P$ I polyimide, $P P O$ polyphenylene oxide, $P U$ polyurethane, $6 F D A-6 F p D A-D A B A$ (4,4-hexafluoroisopropylidene diphthalic anhydride) - (4,4-hexafluoroisopropylidene dianiline) - (3,5-diaminobenzoic acid), SPEEK sulfonated polyether ether ketone, (-) not mentioned

network resulting in additional silica functional groups [53]. Hydrogen bonding between silica particles and the polymer matrix occurs through the interaction between hydroxyl groups existing in the silica molecule with major polymer functional group. Figure 1 shows the hydrogen bonding between $-\mathrm{OH}$ and polyphenylene oxide polymer functional group, illustrated by Zhuang et al. [49]. Silica with hydroxyl group is known as hydrophilic silica, which easily reacts with the polymer matrix through hydrogen bonding.

Interfacial interaction and particle distribution are crucial to determining the textural properties of MMMs. These two factors are capable of adjusting the silica particle arrangement on the polymer surface and ensure the presence of voids or cracks. The formation of interfacial voids indicates incompatibility between the inorganic filler particle with the polymer matrices (Fig. 2a). The selectivity of the MMMs is significantly reduced due to bypassing gases through the surface. In order to rigidify and block those cavities, a strong interfacial linking network and good dispersion should be considered (Fig. 2b). In this case, a bridging or coupling agent is preferable to create a strong interconnection between those phases (Fig. 2c).

A strong interfacial interaction can be created using additional chemicals or coupling agents such as tri(isobutyl) aluminium, undecenoic acid [11], 3-glycidyloxypropyltrim ethoxysilane $[17,49,51,55]$, 3-aminopropyltrimethoxys ilane $[5,16,20,27,31-33,56]$, cis-9-octadecenoic acid [14], octamethylcyclotetrasiloxane [25], sulfonic acid [31, 38], polyethyleneimine [36], 4-aminophenazone [35], nitric acid [42], and polydimethylsiloxane [53] which provide a linking network between the silica and polymer matrices. Generally, the coupling agents are capable of altering the silica particle characteristics from hydrophilic into hydrophobic by replacing the hydroxyl group with typical functional groups. Figure 3 illustrates the replacement of $-\mathrm{OH}$ group using octyl silane (Fig. 3b) and polydimethylsiloxane (Fig. 3c) as reported by Hassanajili et al. [53].

Well-dispersed particles without aggregation should be expected to arrange composite membrane chain packing. Many studies showed that silica particles are generally well distributed with a suitable concentration less than $30 \%$. High silica content tends to create aggregates, increasing cavities and voids between silica particles and polymer matrices. The dispersity of silica particles is affected by the particle size, solvent compatibility, and casting method. Smaller sized particles exhibit high tendency to create agglomeration or aggregation at high concentrations. On the other hand, the solvent used in fabricating membranes should be compatible with the silica particle, so that the desired membrane chain packing arrangement is obtained. Moreover, the selected casting method should be able to guarantee the particle

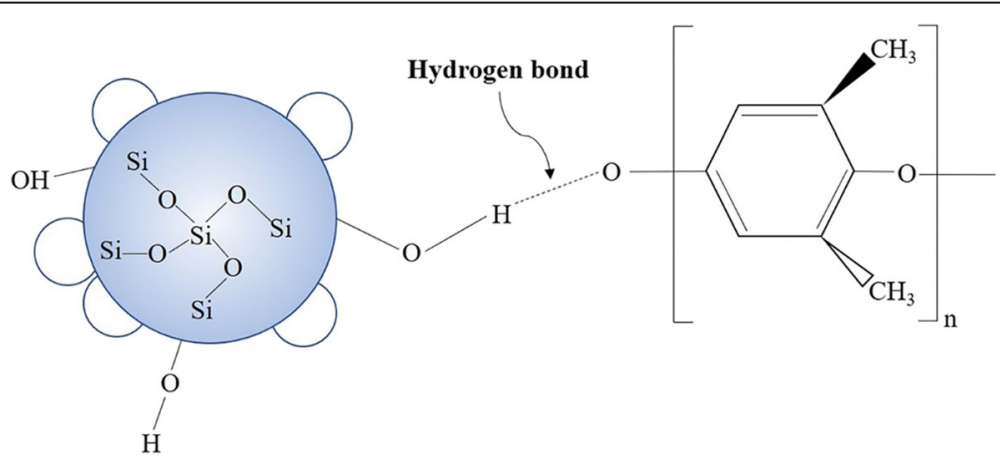

Fig. 1 Schematic hydrogen bonding (dotted line) between silica and polyphenylene oxide matrix [49] 

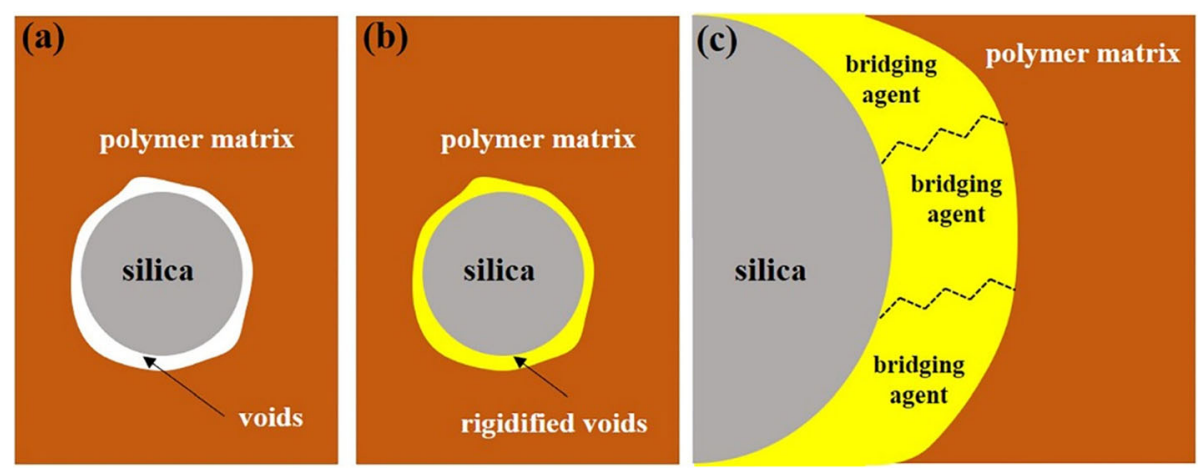

Fig. 2 Interphase properties of MMMs containing silica: (a) void formation, (b) rigidification of void, (c) bridging of the filler and polymer matrix upon surface modification, adapted from Goh et al. [54]

distribution uniformity on the membrane interfacial surface. In case of silica aggregation clusters, Zhuang et al. [49] investigated the preparation method effect on polymer-silica membranes for silica dispersion characteristics. Two types of catalysts were used: acid catalyst (hydrochloric acid) and base catalyst (ammonium hydroxide). Acid catalysed-silica provided smaller microporous silica cluster in polyphenylene oxide matrix while the base catalysed-silica exhibited denser and larger silica clusters.

\section{Gas transport mechanism of MMMs containing silica}

Different silica types provide distinct gas transport paths through MMMs. Two main diffusional paths exist in the gas separation process; namely the Knudsen-diffusion mechanism and solution-diffusion mechanism. Figure 4 illustrates the diffusional pattern of MMMs containing silica with different molecular pore sizes. The Knudsendiffusion mechanism exists typically in a gas transport process through molecular pores inside filler particles. It can also be found when interfacial voids exist between filler particles and polymer matrices. The molecular space or pore size is crucial to determine the type and amount of gases that would be separated. Gas transport through polymer matrices is regularly carried out using the solution-diffusion mechanism, related to the gas molecular ability to penetrate through a polymer surface layer. Solution-diffusion mechanism can also be present by facilitating transport of penetrant gases with respect to high affinity of attached functional groups on silica particle as shown in Fig. 5. The attached functional group acts as a mobile carrier to

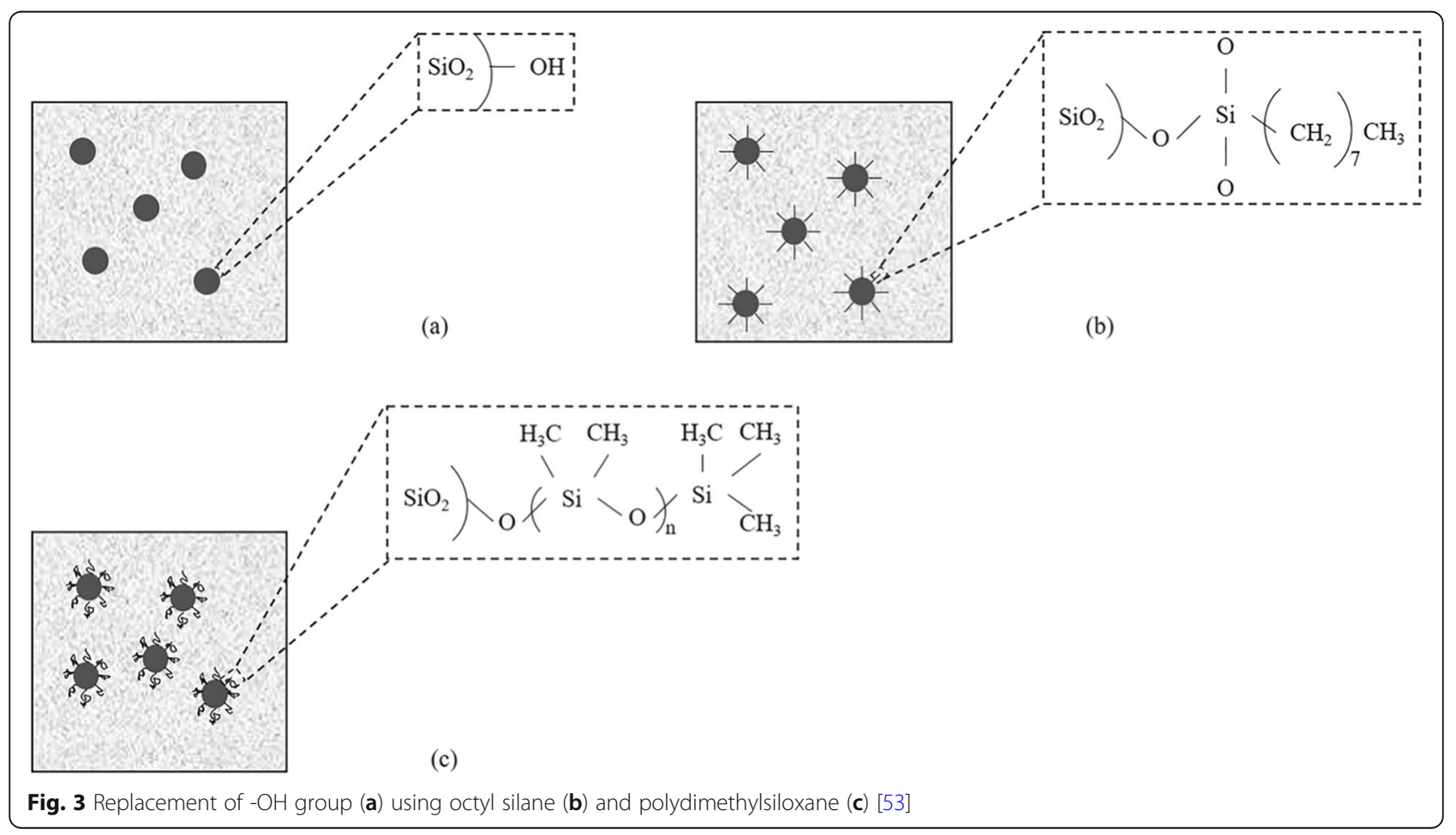



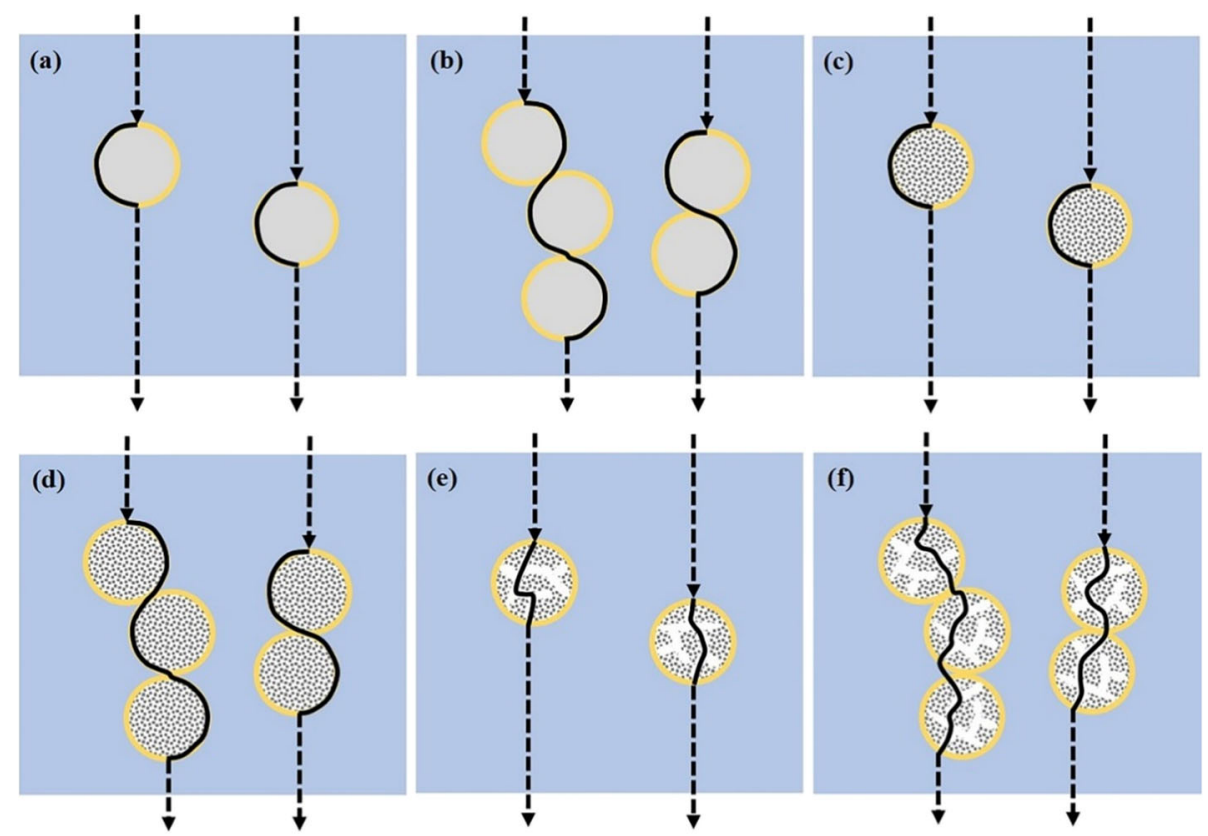

diffusional path controlled by Knudsen diffusion mechanism
$\ldots \ldots \ldots . .$.
diffusional path controlled by Solution-diffusion mechanism

Fig. 4 Diffusional path of mixed matrix membranes containing $(\mathbf{a}, \mathbf{b})$ non-porous silica, $(\mathbf{c}, \mathbf{d})$ microporous silica, (e, $\mathbf{f})$ mesoporous silica, adapted from Park et al. [34]

transport expected penetrant gas through polymer matrix of membrane [57].

Those two diffusion mechanisms could be applied to adjust the permeability and selectivity of composite membranes. The key factors applied are the type of silica and its concentration. Penetrant gases pass through into MMMs containing nonporous silica via non-selective voids between polymer matrix and silica particle as shown in Fig. 6. At low non-porous silica concentration, the solution-diffusion mechanism will be dominant causing increases in membrane selectivity (Fig. 4a) because not enough diffusional path provided by non-selective voids between silica and polymer matrix. As silica content increases, the amount of non-selective void also increases (Fig. 4b), then Knudsendiffusion mechanism will be dominant.

MMMs containing microporous silica exhibit similar diffusional paths compared to the former membrane as shown in Fig. 4c-d. However, Knudsen-diffusion could also occur when the kinetic diameter of gases is compatible with the silica particle pore size (Fig. 7). Only penetrant gases with kinetic diameter less than $2 \mathrm{~nm}$ can pass though pore channel of this microporous silica. Consequently, the solution-diffusion mechanism will be dominant in MMMs containing microporous silica.

Knudsen-diffusion mechanism domination is also available for MMMs with mesoporous silica as the inorganic filler (Fig. 4e-f). The existence of pores with 2-50 $\mathrm{nm}$ of diameter inside silica particles reveals a diffusional-path for gases that elevates the membrane permeability (Fig. 8). The gas permeability in these MMMs is frequently higher than others due to excessive diffusional path provided by mesopores structure of silica and non-selective voids between silica and polymer particle. In some cases, modifying mesoporous silica with suitable functional groups was applied to balance gas permeability and selectivity.

\section{Preferable method for fabricating MMMs containing silica}

Solution blending is the most common method for MMM preparation with silica particle incorporation. In principle, it is a typical solid phase (silica particle and polymer) and liquid phase (solvent) blending process to obtain a homogenous mixture. Silica particles are separately dissolved in solvent, then blended with a polymer solution or concurrently dissolved in solvent with the polymer. An ultrasonic stage is generally carried out to ensure the homogeneity of silica particles onto the polymer matrices. The solution blending method is generally suitable for non-porous silica (fumed silica) and mesoporous silica (MCM-41). The selected solvent should be able to completely dissolve two kinds of solid phases into a liquid phase and achieve good particle dispersity. Various kinds of solvents have been applied for fabricating polymer-silica membranes such as 


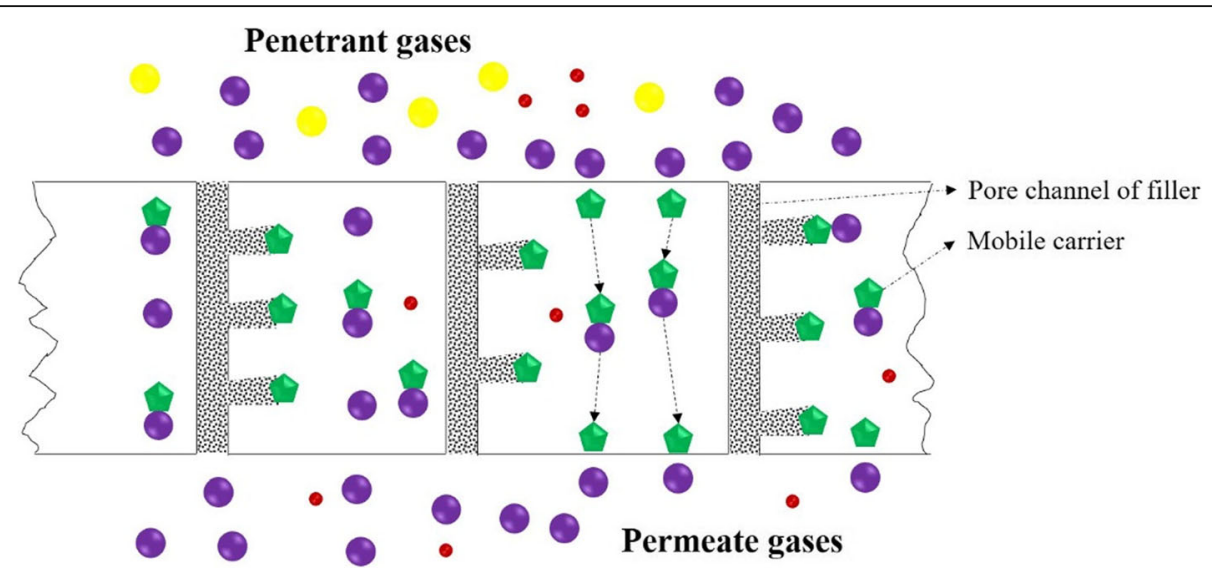

Fig. 5 Solution-diffusion mechanism by facilitated transport MMMs, adapted from Salim and Ho [57]

chloroform [9, 19, 21, 31, 32, 34, 35, 54, 58], dimethylformamide [12, 33, 38, 48], acetic acid [13], N-methyl-2-pyrrolidinone $[5,22,24,39,43]$, tetrahydrofuran $[25,30,34$, 42 , 52], toluene [23], dimethylacetamide [6, 18, 47, 53, 55], ethanol/water [14, 36], acetone [47], propanol [59], and 1, 10-diiododecane [60].

The in-situ sol gel method is suitable for fabricating MMMs that uses a liquid silica precursor. Silica particles could be synthesized by hydrolysing a chemical precursor such as tetraethyl orthosilicate, aminopropyltriethoxysilane, and sodium metasilicate to produce silica sol. Figure 9 clearly describes the in-situ sol gel method for fabricating polyphenylene oxide-silica composite membrane [49]. First, the polymer solution is prepared by dissolving in solvent. Tetraethyl orthosilicate is hydrolysed by adding ethanol and acid or base as the catalyst, followed with stirring for several hours at a certain temperature. These two solutions are then mixed with continuous stirring under the same conditions.
In the polymerization method, a monomer is polymerized around and between silica particles in a liquid phase as shown in Fig. 9. The silica particles are generally modified with a co-monomer before the polymerization reaction to improve compatibility with the polymer matrix through chain entanglement and interaction on the interface. Modified silica is expected to connect with the polymer matrix, showing better compatibility compared to the solution blending method. The polymerization reaction could be initiated by thermal activation, ultraviolet radiation, enzymatic activation, or initiator and curing agent incorporation [56]. Polymerization by initiator incorporation can be considered as a simple way to prepare polymer-silica membranes. A study prepared polyethylene/MCM-41 membranes via in-situ polymerization by incorporating an initiator and curing agent. In this study, undecenoic acid and tri(isobutyl) aluminium as the co-monomeric unit or coupling agent were used to enhance interface adhesion in polyethylene/MCM-41 membranes using ethylene in-situ

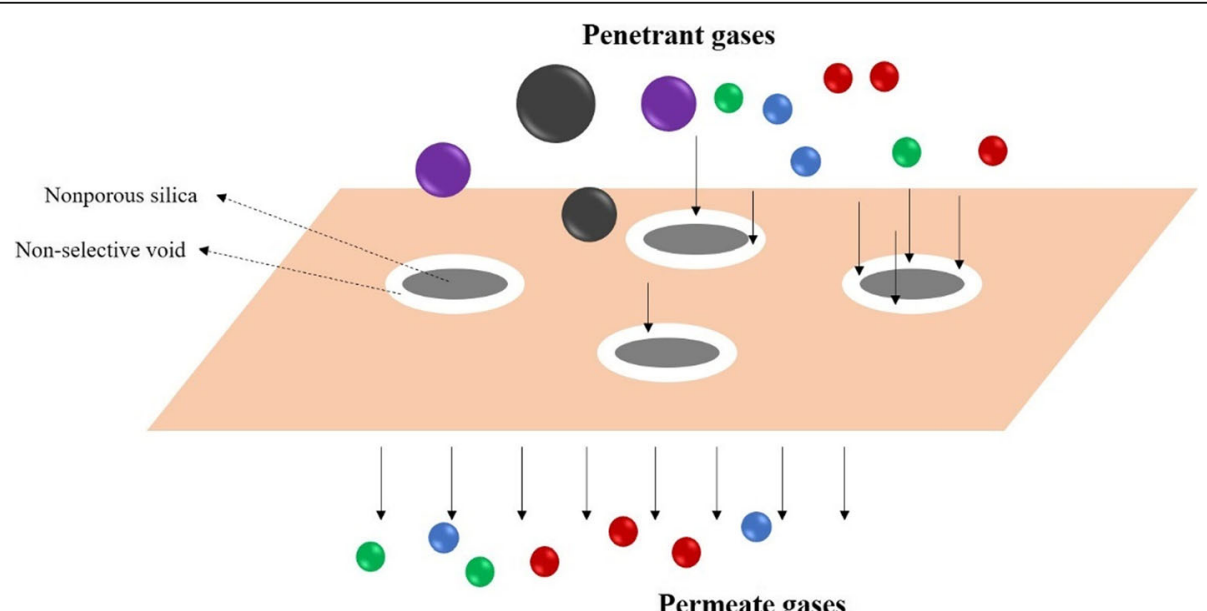

Permeate gases

Fig. 6 Gas transport mechanism of penetrant gases through MMMs containing nonporous silica with non-selective voids 


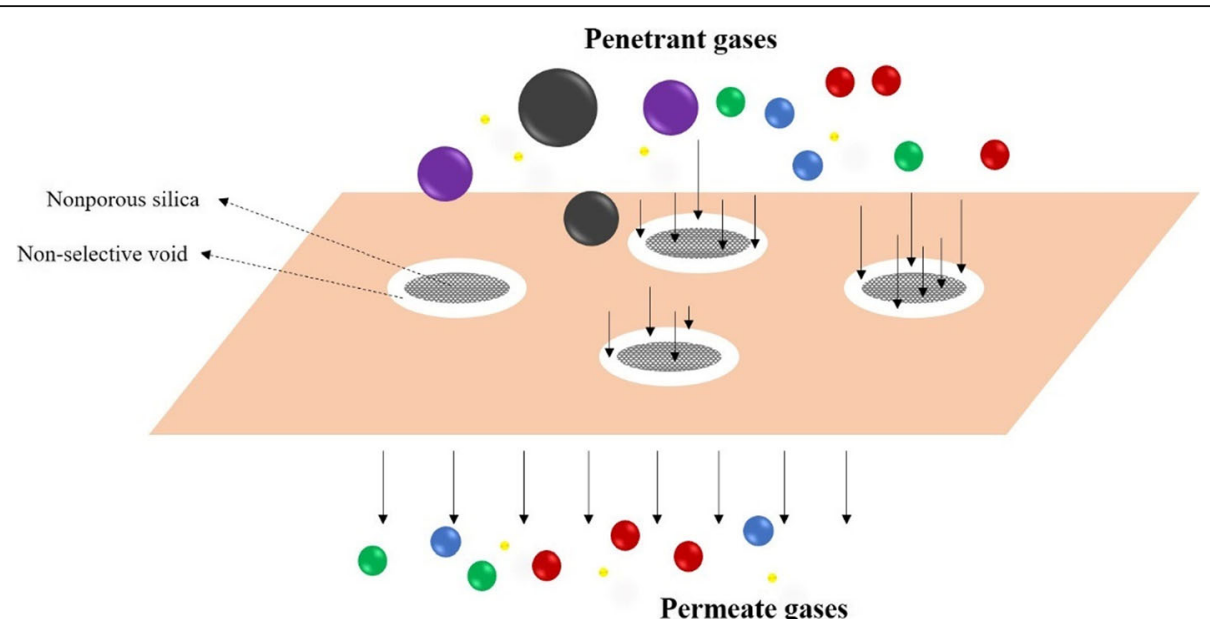

Fig. 7 Gas transport mechanism of penetrant gases through MMMs containing microporous silica with non-selective voids

polymerization [11]. There are three polymerization method used in this study, denoted as method A, method $\mathrm{B}$, and method $\mathrm{C}$. In method $\mathrm{A}$, the process is started with co-polymerization of ethylene with undecenoic acid and tri(isobutyl) aluminium catalysed by $\mathrm{Cp}_{2} \mathrm{ZrCl}_{2} /$ methyl aluminoxane under homogeneous conditions in the presence of unmodified MCM-41. Methods B and C were initiated by MCM- 41 modification with undecenoic acid and tri(isobutyl) aluminium, followed by ethylene polymerization with zircon catalyst as the initiator under homogeneous conditions.

A preferable method for fabricating MMMs containing silica could be determined by the type of silica, ease and processability, particle dispersity, and prominent parameters. Table 4 illustrates all considerations among three MMM fabrication methods. As mentioned in previous section regarding interfacial interaction of silica and polymer matrix, membrane surface properties should be considered to achieve high gas separation performance. Therefore, the MMM fabrication method is chosen based on its ability to ensure good silica particle dispersity in the polymer matrix. Table 4 indicates that in-situ sol gel and in-situ polymerization are preferable due to their abilities to create high interconnectivity between the silica particles and polymer matrix. However, the coupling agent such as undecenoic acid and tri(isobutyl) aluminium might be required to improve these interactions.

\section{Silica load effect on MMM characteristics and performance \\ Thermal stability of MMMs containing silica}

Thermal stability is related to the temperature range that a membrane still retains its useful properties in a given application. Thermogravimetric analysis is usually used to determine the decomposition temperature in terms of

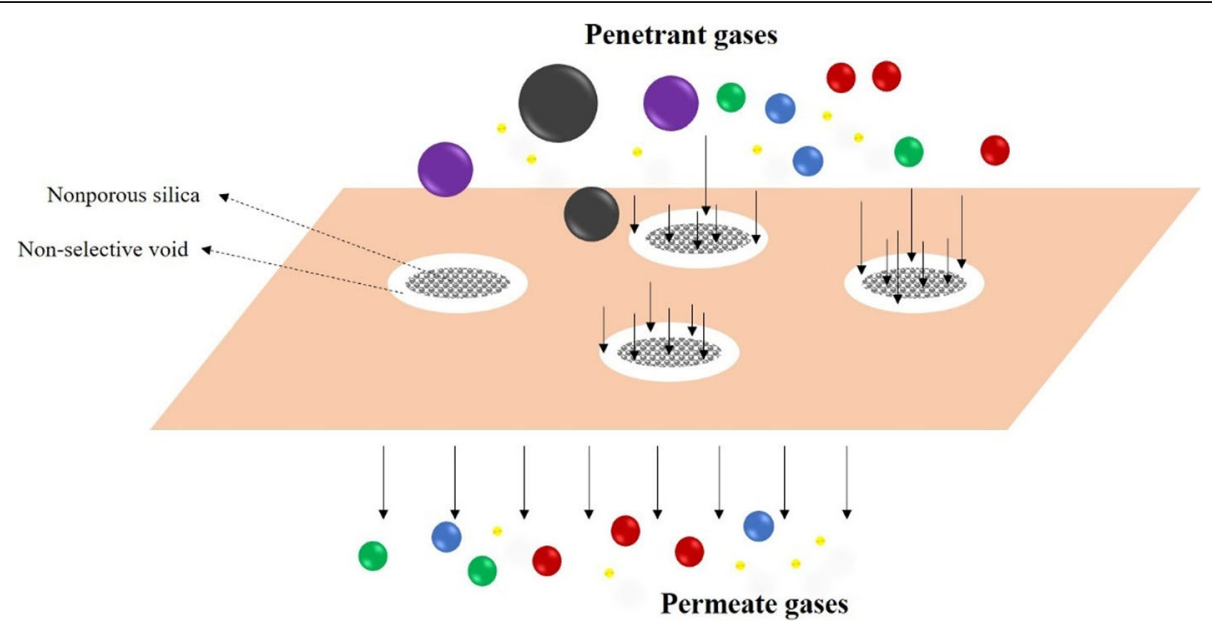

Fig. 8 Gas transport mechanism of penetrant gases through MMMs containing mesoporous silica with non-selective voids 


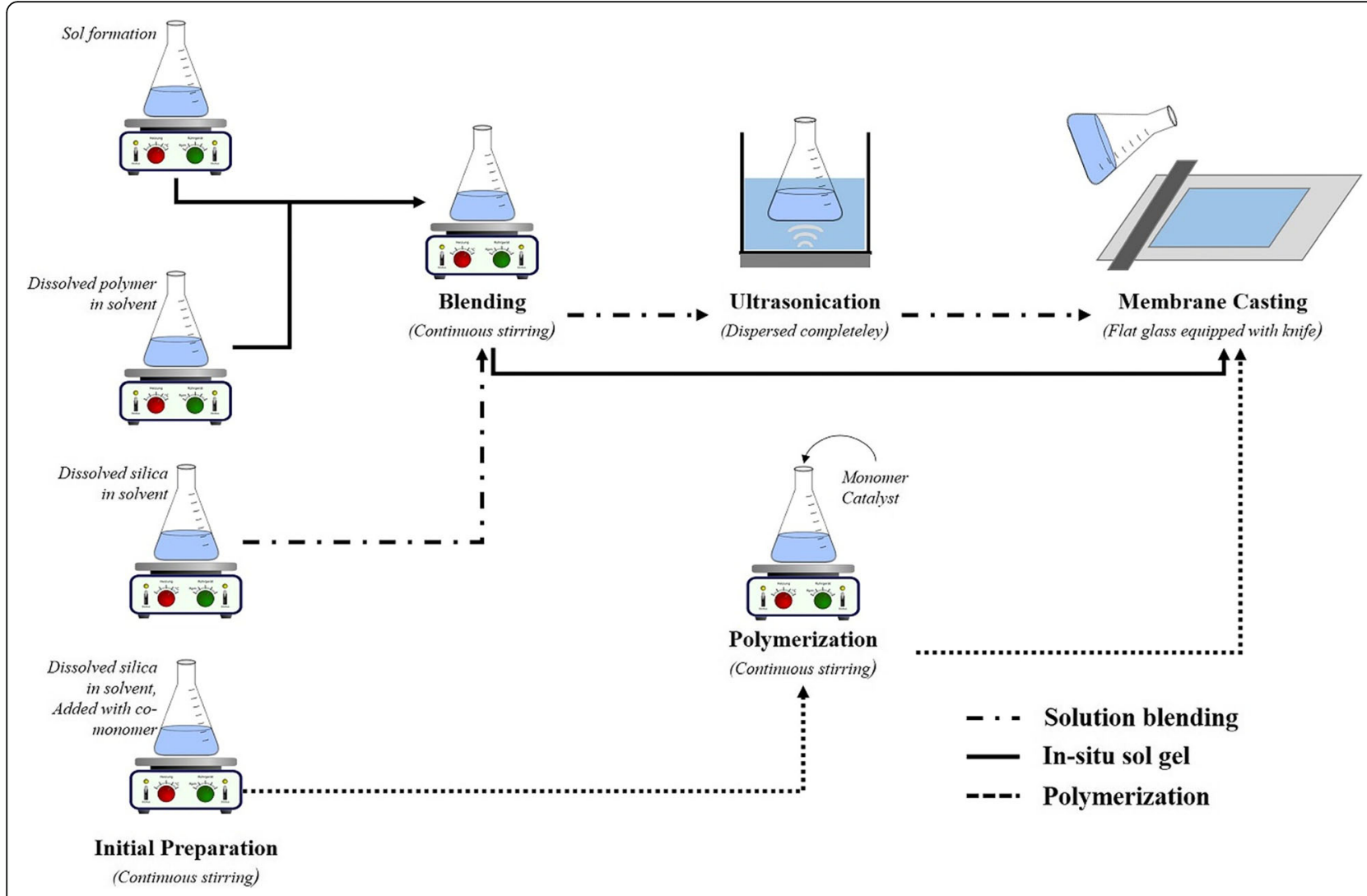

Fig. 9 Different MMM preparation methods

membrane thermal stability. Many studies have reported the influence of silica content on MMM thermal stability. The decomposition temperatures of MMMs containing silica in the $400-650^{\circ} \mathrm{C}$ range are shown in Fig. 10. Thermal stability enhancement occurs when silica particles are applied into polysulfone/polyimide [16], polyphenylene oxide [49], polyethylene [58], and hyperbranched polybenzoxazole (both of 6FAHP-BTC hyperbranched polybenzoxazole and 6FAHP-OBC hyperbranched polybenzoxazole) [61]. Significant improvement occurs when silica particles are incorporated into a thermoplastic polymer such as polyethylene [58]. The thermal stability improvement is related to the strong interaction among the organic materials and inorganic fillers, forming a chemical bonded network structure in hybrids. This interaction is able to hinder the mobility of polymer chains so that the decomposition temperature is increased after silica addition [49]. Other studies reported that a decreasing trend was observed in MMMs containing silica particles. Two types of silica (fumed silica and mesoporous silica) decreased the thermal stability of polyvinylidene fluoride membranes [5]. This is probably caused by the interaction between the silica particles with polymer substance product degradation, which could elevate the decomposition process.

Table 4 Comparison between three MMM fabrication methods containing silica

\begin{tabular}{|c|c|c|c|}
\hline Parameter & Solution blending & In-situ sol gel & In-situ polymerization \\
\hline Type of silica & $\begin{array}{l}\text { Solid/powder of silica (fumed } \\
\text { silica } \\
\text { and mesoporous silica) }\end{array}$ & Silica sol (microporous silica) & $\begin{array}{l}\text { Solid/powder of silica (fumed } \\
\text { silica and } \\
\text { mesoporous silica) }\end{array}$ \\
\hline $\begin{array}{l}\text { Type of treatment/ } \\
\text { reaction }\end{array}$ & Mechanical stirring & $\begin{array}{l}\text { Chemical reaction (sol formation) } \\
\text { - Mechanical stirring }\end{array}$ & $\begin{array}{l}\text { Mechanical stirring - Chemical } \\
\text { reaction } \\
\text { (polymerization) }\end{array}$ \\
\hline Dispersity of silica & $\begin{array}{l}\text { Low dispersity, need additional } \\
\text { treatment (ultrasonication) }\end{array}$ & Good dispersity of particle & $\begin{array}{l}\text { High interconnectivity between } \\
\text { silica particle and polymer matrix }\end{array}$ \\
\hline Prominent factor & Solvent selection & $\begin{array}{l}\text { Compatibility of polymer with silica functional } \\
\text { group, sometimes need a coupling agent }\end{array}$ & $\begin{array}{l}\text { Compatibilizing agent e.g., undecenoic } \\
\text { acid, tri(isobutyl) aluminium }\end{array}$ \\
\hline
\end{tabular}




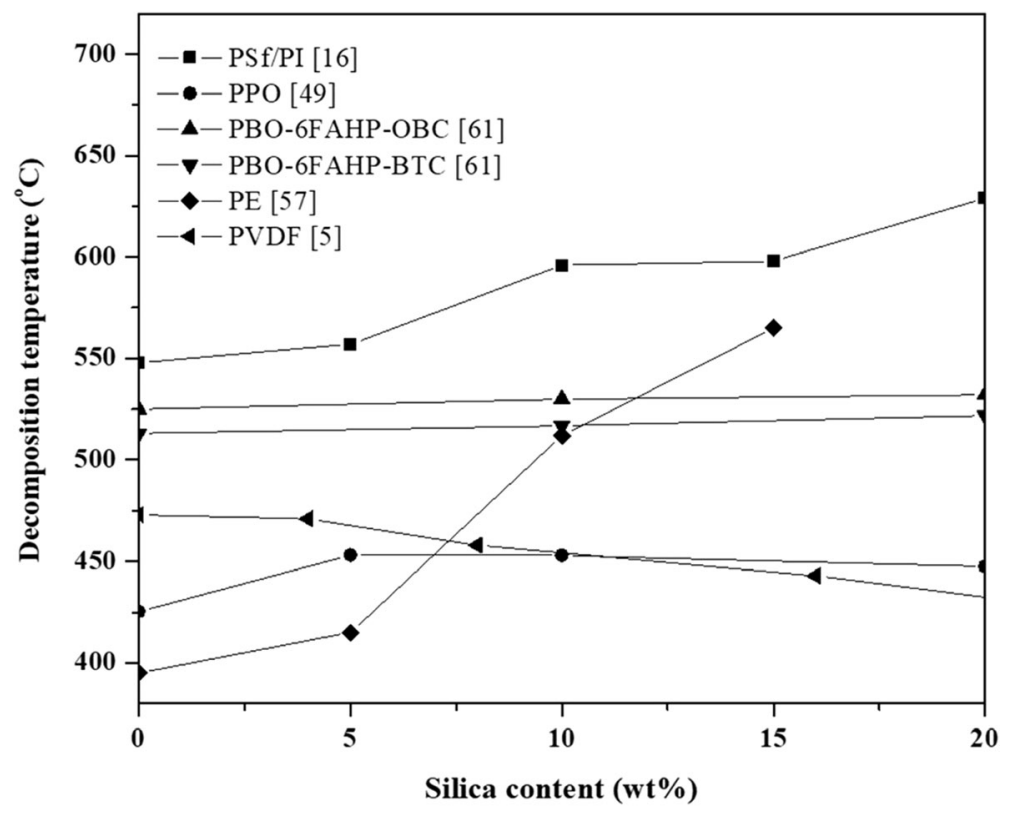

Fig. 10 The enhancement of decomposition temperature of MMMs comprising silica particle (PSf/PI: polysulfone/polyimide; PPO: polyphenylene oxide; PBO-6FAH-OBC: (polybenzoxazole) - (2,2-bis 3-amino-4-hydro-xyphenyl hexafluoropropane) - (4,4'-oxybis benzoic acid chloride); PBO-6FAHBTC: (polybenzoxazole) - (2,2-bis 3-amino-4-hydro-xyphenyl hexafluoropropane) - (1,3,5-benzenetricarbonyltrichloride); PE: polyethylene; PVDF: polyvinylidene fluoride)

\section{Mechanical properties of MMMs containing silica}

Mechanical properties are related to the membrane ability to withstand physical defects, including tensile stress, tensile modulus, elongation at break, and decomposition temperature. Tensile stress is the maximum stress that a membrane can handle. Tensile modulus is related to the stress state leading to expansion. The elongation at break means the elongation that a material can withstand before breaking. All mechanical property parameters are generally related to silica particle compatibility with the polymer matrix.

Significant effect on tensile stress and tensile modulus can be observed in polymeric membranes with increasing silica content, as shown in Figs. 11 and 12. Lua and Shen [6] have investigated the mechanical properties of polyimide membranes with silica incorporation. The polyimide concentration was fixed at $12 \mathrm{wt} \%$ while silica particle loading was varied from 1.5 to $13.7 \mathrm{wt} \%$. The tensile stress and tensile modulus of polyimide membranes are significantly increased with increasing silica content. This was also observed when silica particles (5-20 wt\%) are incorporated into polyethylene (15 wt\%) and polyether block amide (4wt\%) matrices, even though with a slightly increasing trend. This enhancement was due to the transfer of external force on the composite materials from the polymer matrix (continuous phase) to the inorganic phase (discontinued phase), determining the degree of compatibility between those two materials [6]. The contradictive effect of silica particles on tensile stress and tensile modulus was observed on polyvinylidene fluoride (2wt\%) membranes. Poor compatibility between a high amount of silica particles and polyvinylidene fluoride polymer was believed to be the primary factor in polymer chain tenacity deterioration by inorganic fillers [5]. Therefore, the interfacial interaction between inorganic fillers and polymer matrix should be considered as a key factor affecting the tensile stress and tensile modulus values.

MMM elongation at break depends highly on the inorganic filler ability to restrict polymer chain movement and avoid the occurrence of large macroscale extension [6]. Lower MMM elongation at break implies the silica content in the polymer matrix is enough to limit chain packing movement, supported by strong interfacial interaction. Polyimide membranes provide higher tensile stress and tensile modulus as the silica content is increased (Figs. 11 and 12), which implies good compatibility between the two phases materials. Thus, the elongation at break of membranes would decrease with increasing silica content (Fig. 13). Conversely, an increasing elongation at break trend is observed with polyvinylidene fluoride with a high silica load [5]. This indicates that the polymer chain could still be flexible to extend or move due to weak interfacial interaction among the polymer and fillers.

Silica particles provide significant MMM mechanical property effects based on the original polymer. If the polymer properties exhibit a rigid structure with high crystallinity, it would be easier to adjust the tensile stress, modulus, and elongation at break by incorporating silica particles. However, silica particles fail to alter 


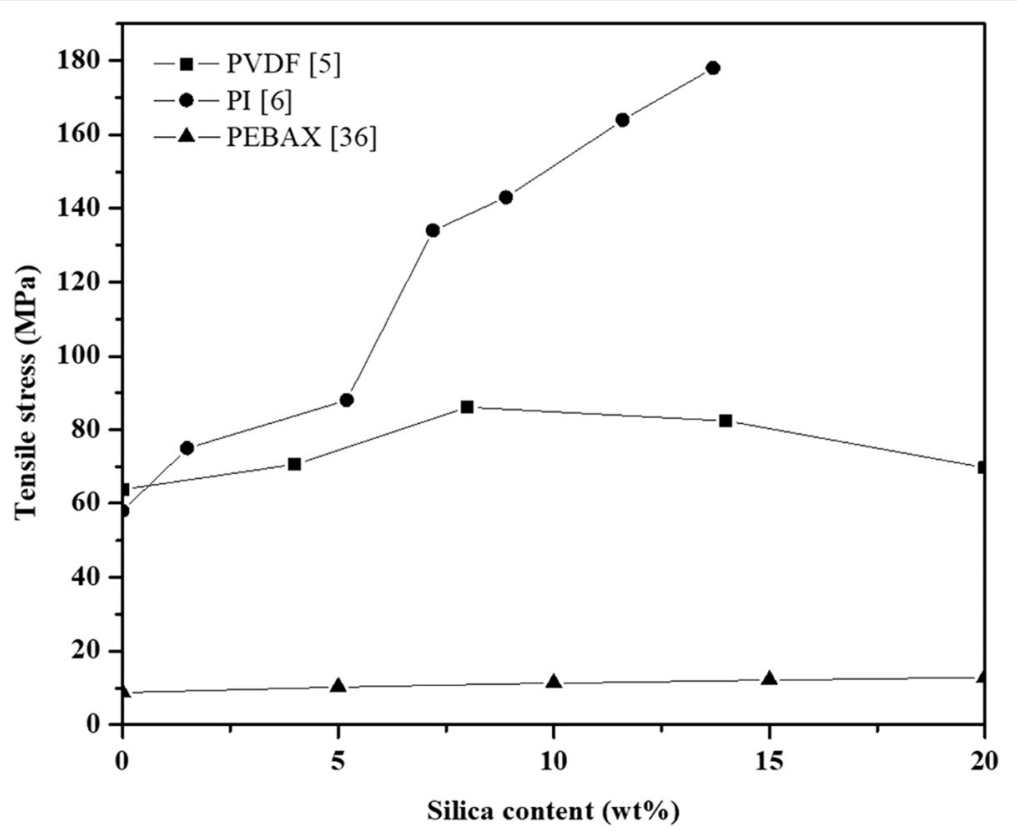

Fig. 11 Tensile stress of MMMs containing silica (PVDF: polyvinylidene fluoride; PI: polyimide; PEBAX: polyether block amide)

the mechanical properties of semi-crystalline polymers at the maximum load of $15-20 \mathrm{wt} \%[5,36]$.

\section{Silica load effect on MMM gas permeability and selectivity}

It is believed that silica particles provide a significant effect on MMM gas permeability. Several studies have investigated the gas separation performance of MMMs with various amounts of silica content. In principle, the silica load should be maintained at maximum $30 \mathrm{wt} \%$ to avoid a brittle structure in the fabricated membranes [19], even though several studies applied a little higher $30 \mathrm{wt} \%$ silica load. Optimum gas permeability is also commonly achieved at the highest silica load. In addition, silica particle affinities should be considered in creating hydrogen bonding between the functional group

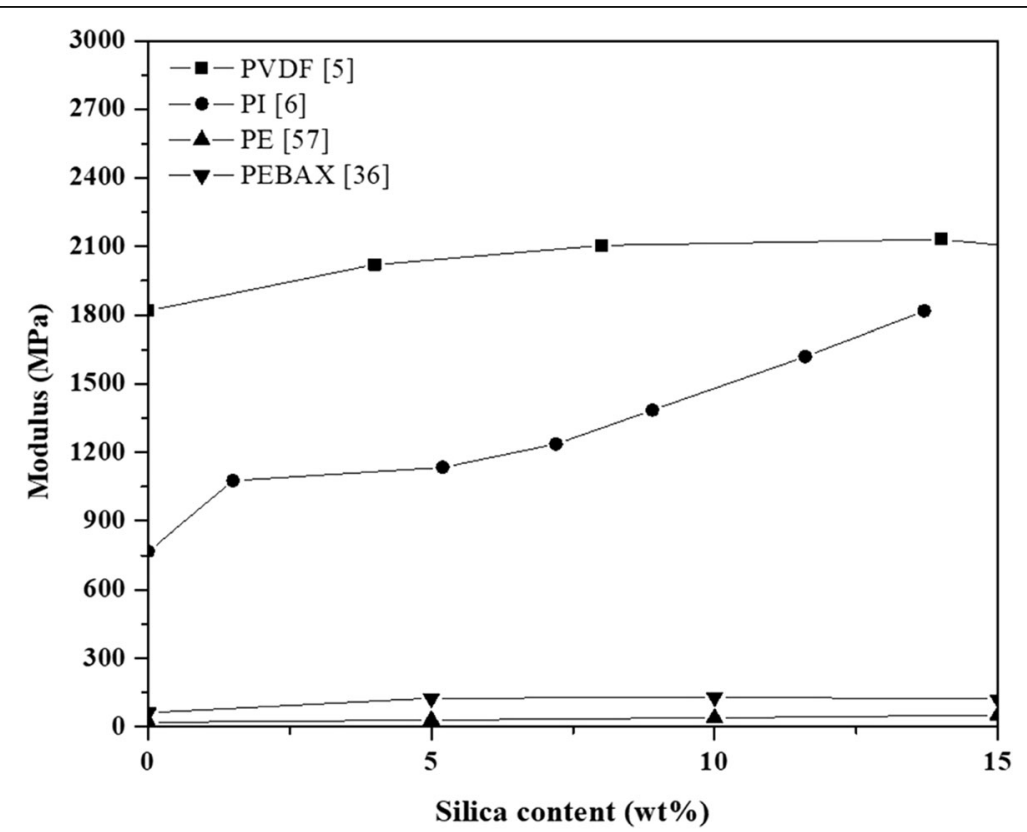

Fig. 12 Tensile modulus of MMMs containing silica (PVDF: polyvinylidene fluoride; PI: polyimide; PE: polyethylene; PEBAX: polyether block amide) 


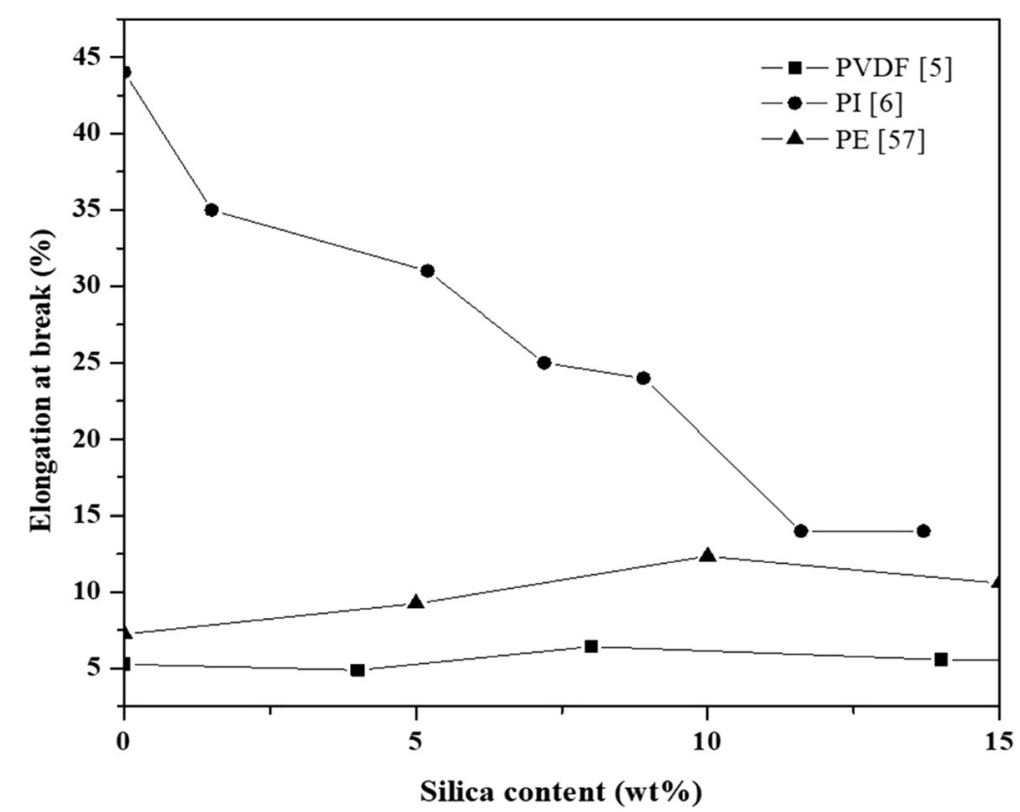

Fig. 13 Elongation at break of MMMs containing silica (PVDF: polyvinylidene fluoride; PI: polyimide; PE: polyethylene)

on silica particle as active sites with penetrant molecules (polar gases), affecting increased permeability. Consequently, MMMs exhibit higher permeability for $\mathrm{CO}_{2}$ and $\mathrm{H}_{2}$ compared to other gases, as shown in Table 5 .

In the non-porous silica case, the permeability for all tested gases with several polymeric membranes could be improved by silica particle incorporation, as shown in Table 5 . The optimum gas permeability was achieved at the highest silica load. This result was obviously contradictive with the Maxwell theory, which predicted that the gas permeability of a MMM containing non-porous filler should be lower than that of the pure polymer and still decreased with higher filler content due to higher polymer matrix tortuosity [8]. Ahn et al. [19] explained that the presence of void volume at the nano particlepolymer interface became the primary factor in gas permeability enhancement in polymers of intrinsic microporosity MMMs. Shen and Lua [24] considered other reasons to explain this phenomenon, related to free volume theory. This theory explained that non-porous silica was able to disrupt the polymer chain packing and increase the polymer free volume. The nano sized nonporous silica provided appropriate sites on the interface with the polymer chains for gas adsorption, hence resulting in increasing gas permeability [62].

MMM gas permeability was also enhanced by increasing the microporous silica load. Sadeghi et al. [17] and Zhuang et al. [49] considered crystallinity and active site to describe the microporous silica effect on MMM gas permeability. The crystallinity of polyphenylene oxide matrix decreased upon the addition of microporous silica, creating more amorphous regions that could improve gas diffusion. Chemical bonding between the silica and polymer chains was able to enhance d-spacing, which could increase gas solubility. Therefore, the gas permeability of MMMs was enhanced at high microporous silica load. Meanwhile, Kwon et al. [26], Xin et al. [38], Suzuki and Yamada [61] tended to consider fraction free volume for describing the enhancement of 6FpDA-DABA hyperbranched hexafluoroisopropylidene, sulfonated polyether ether ketone, and 6FAHP-BTC hyperbranched polybenzoxazole gas permeability, respectively. Microporous silica particles might disrupt the polymer chain packing and increase the free volume between polymer chains, increasing gas diffusion, thus improving gas permeability.

Mesoporous silica also provided enhancement in gas permeability for several other polymeric membranes, as shown in Table 5. Larger mesoporous silica pore size provided easy passage for all gas penetrants, thus the increasing diffusion coefficient could be obtained at high mesoporous silica load $[36,58]$. Similar with the previous silica types, Laghaei et al. [33] considered phenomena such as polymer chain packing disruption and crystal phase nucleation to explain the mesoporous silica effect on polyethersulfone membrane gas permeability. Polymer chain packing disruption is related to fraction free volume enhancement while crystal phase nucleation corresponds to the formation of an amorphous region in the membrane structure. On the other hand, Zornoza et al. [9] offered two factors that explain the increase in permeability with mesoporous silica load: the difference in permeability between the filler and polymer and changes induced by the filler in the polymer structure. 
Table 5 Optimum gas permeability of several mixed matrix membranes containing silica particles

\begin{tabular}{|c|c|c|c|c|c|c|c|c|c|}
\hline \multirow[t]{2}{*}{ Type of silica } & \multirow[t]{2}{*}{ Polymer matrix } & \multirow[t]{2}{*}{$\begin{array}{l}\text { Range of } \\
\text { silica loading (\%) }\end{array}$} & \multirow[t]{2}{*}{$\begin{array}{l}\text { Optimum silica } \\
\text { loading (\%) }\end{array}$} & \multicolumn{4}{|c|}{$\begin{array}{l}\text { Optimum permeability } \\
\left(\times 10^{-10} \mathrm{~mol} \mathrm{~m}^{-1} \mathrm{~s}^{-1} \mathrm{MPa}^{-1}\right)\end{array}$} & \multirow[t]{2}{*}{$\begin{array}{l}\text { Measurement } \\
\text { condition }\end{array}$} & \multirow[t]{2}{*}{ Ref } \\
\hline & & & & $\mathrm{CO}_{2}$ & $\mathrm{O}_{2}$ & $\mathrm{CH}_{4}$ & $\mathrm{H}_{2}$ & & \\
\hline \multirow[t]{7}{*}{ Non-porous silica } & PIM-1 & $6.7-23.5$ & 23.5 & 44,890 & $12,495.5$ & - & $24,086.5$ & $23^{\circ} \mathrm{C} 0.345 \mathrm{MPa}$ & {$[19]$} \\
\hline & PVDF & $4-32$ & 32 & 8.88 & 1.20 & - & - & - & [5] \\
\hline & P84 co-polyimide & $4-25$ & 25 & 10.02 & 6.77 & - & - & - & {$[24]$} \\
\hline & ETPU & $5-15$ & 15 & 16.21 & - & 1.27 & - & $25^{\circ} \mathrm{C} 0.6 \mathrm{MPa}$ & {$[44]$} \\
\hline & ESPU & $5-15$ & 15 & 28.60 & - & 1.74 & - & & \\
\hline & $\mathrm{PU}$ & $1-10$ & 1 & 150.75 & 17.09 & 22.45 & - & $25^{\circ} \mathrm{C} 0.1-0.4 \mathrm{MPa}$ & [59] \\
\hline & PSf & $5-20$ & 20 & 66.00 & 16.75 & 3.69 & - & - & {$[62]$} \\
\hline \multirow[t]{6}{*}{ Microporous silica } & $\mathrm{PBI}$ & $2.8-20$ & 20 & 0.04 & - & 0.03 & - & $25^{\circ} \mathrm{C} 2 \mathrm{MPa}$ & {$[17]$} \\
\hline & 6FDA-6FpDA-DABA & $0.5-3.0$ & 1 & 93.80 & 20.10 & - & - & $35^{\circ} \mathrm{C} 0.1 \mathrm{MPa}$ & {$[26]$} \\
\hline & SPEEK & $5-20$ & 20 & 87.44 & - & 5.03 & - & $25^{\circ} \mathrm{C} 0.2 \mathrm{MPa}$ & {$[38]$} \\
\hline & PPO & $1-20$ & 20 & 4465.55 & - & - & $13,085.1$ & $25^{\circ} \mathrm{C} 0.2 \mathrm{MPa}$ & [49] \\
\hline & PU & $2.5-30$ & 2.5 & 223.45 & 12.70 & 12.13 & - & $20^{\circ} \mathrm{C} 1 \mathrm{MPa}$ & {$[50]$} \\
\hline & PBO-6FAHP-BTC & $10-20$ & 20 & 2388.55 & 375.20 & 921.25 & - & $25^{\circ} \mathrm{C} 0.1 \mathrm{MPa}$ & {$[61]$} \\
\hline \multirow[t]{9}{*}{ Mesoporous silica } & $\mathrm{Pl}$ & $4-16$ & 8 & 50.25 & - & 81.07 & 46.57 & $35^{\circ} \mathrm{C} 0.175 \mathrm{MPa}$ & [9] \\
\hline & & $1.5-13.7$ & 13.7 & 4.92 & 1.94 & - & - & $25^{\circ} \mathrm{C}$ & [6] \\
\hline & PE & $7.9-10.3$ & 8.6 & 64.99 & 21.51 & - & - & $30^{\circ} \mathrm{C}$ & {$[11]$} \\
\hline & PVDF & $4-32$ & 32 & 9.55 & 1.37 & - & - & - & [5] \\
\hline & PES & $5-20$ & 20 & 12.93 & 2.18 & 0.44 & - & $25^{\circ} \mathrm{C} 0.8 \mathrm{MPa}$ & [33] \\
\hline & PSf & $10-20$ & 20 & 95.48 & - & 4.92 & - & $35 \mathrm{MPa}$ & [34] \\
\hline & 6FDA-DAM-DABA & $10-20$ & 20 & 1222.42 & - & 37.19 & - & & \\
\hline & PEBAX & $5-20$ & 20 & 2519.2 & - & 132.66 & - & $25^{\circ} \mathrm{C} 0.2 \mathrm{MPa}$ & {$[36]$} \\
\hline & PEBAX/PEI & $5-20$ & 20 & 5095.35 & - & 124.29 & - & & \\
\hline
\end{tabular}

PIM-1 soluble type of polymers of intrinsic micro porosity, PVDF polyvinylidene fluoride, P84 co-polyimide BTDA-TDI/MDI co-polyimide, ETPU polyetherurethane, ESPU polyesterurethane, $P U$ polyurethane, PSf polysulfone, $P B I$ polybenzimidazole, 6FDA-6FPDA-DABA (4,4-hexafluoroisopropylidene diphthalic anhydride) - (4,4hexafluoroisopropylidene dianiline) - (3,5-diaminobenzoic acid), SPEEK sulfonated polyether ether ketone, PBO-6FAHP-BTC (polybenzoxazole) - (2,2-bis 3-amino-4hydro-xyphenyl hexafluoropropane) - (1,3,5-benzenetricarbonyltrichloride), PI polyimide, PE polyethylene, PVDF polyvinylidene fluoride, PES polyestersulfone, 6FDA-DAM-DABA (4,4'hexafluoroisopropylidene diphthalic anhydride) - (2,4,6-trimethyl-1,3-diaminobenzene) - (3,5-diaminobenzoic acid), PEI polyethyleneimine, PEBAX polyether block amide. (-) not mentioned

Gas selectivity is related to the MMM ability to hinder a gas molecule from passing through the membrane surface. This could be calculated by dividing two gas permeability values. We focused only on three categories of gas selectivity: $\mathrm{CO}_{2} / \mathrm{CH}_{4}, \mathrm{H}_{2} / \mathrm{CO}_{2}$, and $\mathrm{H}_{2} / \mathrm{CH}_{4}$. The other gas pairs such as $\mathrm{CO}_{2} / \mathrm{N}_{2}, \mathrm{~N}_{2} / \mathrm{CH}_{4}, \mathrm{O}_{2} / \mathrm{N}_{2}$ were not discussed because the trade-off relationship still occurred among MMMs for those gas pairs. The use of $\mathrm{CO}_{2} / \mathrm{CH}_{4}$ and $\mathrm{H}_{2} /$ $\mathrm{CO}_{2}$ is generally to determine the ability to purify methane or syngas from carbon dioxide gas in HHMs, whereas $\mathrm{H}_{2}$ / $\mathrm{CH}_{4}$ selectivity is suitable to consider the MMM ability to separate hydrogen and methane as two biofuel precursors. Those three MMM selectivity categories are compared to the Robeson's upper bound [63] to evaluate the trade-off relationship between gas permeability and selectivity.

In terms of $\mathrm{CO}_{2} / \mathrm{CH}_{4}$ selectivity, nearly all MMMs containing silica particles still exhibit the trade-off relationship in gas separation performance, which was not able to exceed the Robeson's upper bound line as shown in Fig. 14.
Only DAM-DABA hyperbranched hexafluoroisopropy lidene membrane [34] and 6FAHP-OBC hyperbranched polybenzoxazole membrane [61] showed higher selectivity beyond the Robeson's upper bound. The optimum selectivities of those membranes were 36.2 and 48.7, respectively. In DAM-DABA hyperbranched hexafluoroisopropylidene containing $10 \mathrm{wt} \%$ disordered mesoporous silica (DMS), the lower concentration of mesoporous particles could maintain the solution-diffusion mechanism, supported by low resistance to gas flow through mesoporous channels [34]. On the other hand, Suzuki and Yamada [61] explained that superior $\mathrm{CO}_{2} / \mathrm{CH}_{4}$ selectivity could be achieved using high free volume holes provided by the hyperbranched structure. This was created around 6FAHP-OBC hyperbranched polybenzoxazole polymer and silica interfacial area, supported with typical interconnectivity advantageous for $\mathrm{CO}_{2} / \mathrm{CH}_{4}$ separation process.

For $\mathrm{H}_{2} / \mathrm{CO}_{2}$, there are two MMMs that could be compared, soluble form of polymers of intrinsic microporosity 


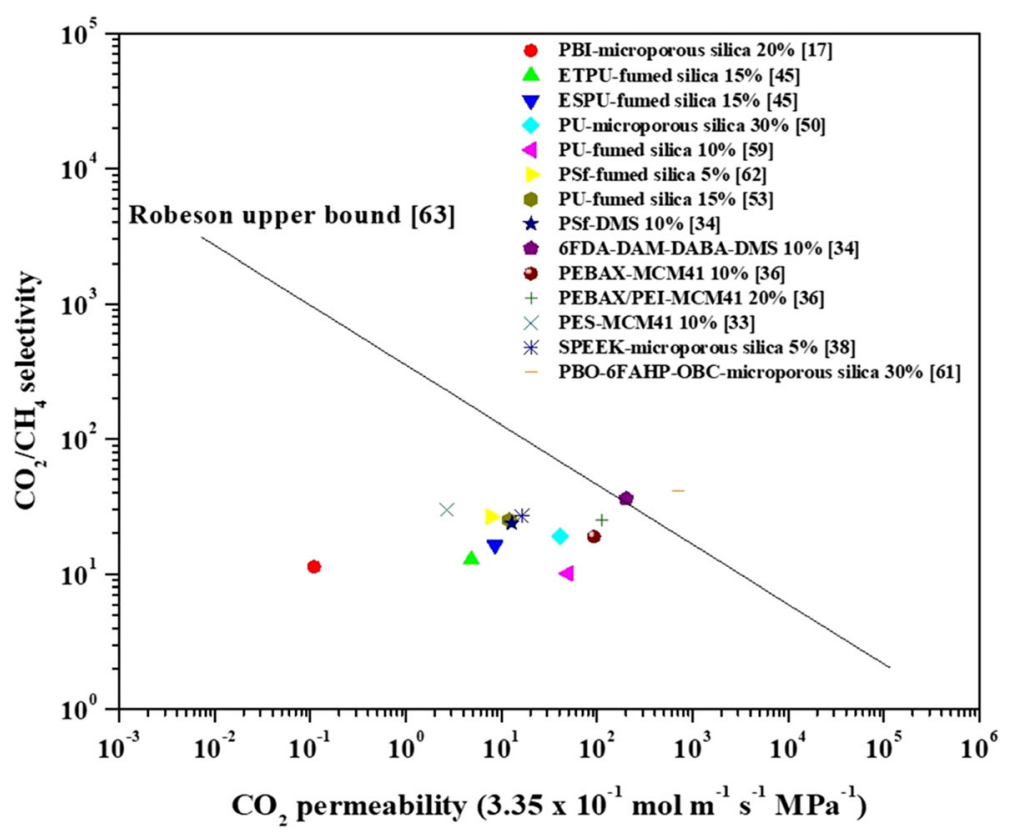

Fig. $14 \mathrm{CO}_{2} / \mathrm{CH}_{4}$ selectivity of MMMs compared to Robeson upper bound [63] (PBI: polybenzimidazole; ETPU: polyetherurethane; ESPU: polyesterurethane; PU: polyurethane; PSf: polysulfone; 6FDA-DAM-DABA: (4,4'hexafluoroisopropylidene diphthalic anhydride) - (2,4,6-trimethyl-1,3diaminobenzene) - (3,5-diaminobenzoic acid); PEBAX: polyether block amide; PEl: polyethyleneimine; PES: polyethersulfone; SPEEK: sulfonated polyether ether ketone; PBO-6FAHP-OBC: (polybenzoxazole) - (2,2-bis 3-amino-4-hydro-xyphenyl hexafluoropropane) - (4,4'-oxybis benzoic acid chloride)

membrane [19] and polyphenylene oxide membrane [49]. As shown in Fig. 15, polyphenylene oxide membrane with $10 \mathrm{wt} \%$ micro porous silica was able to achieve high MMM performance exceeding the Robeson's upper bound with 3.56 of $\mathrm{H}_{2} / \mathrm{CO}_{2}$ selectivity. Zhuang et al. [49] correlated the fabrication method of this MMMs with its gas separation performance. In-situ sol gel method was believed to fabricate the non-defect polyphenylene oxidesilica MMMs, thus the trade-off relationship could be defeated. Meanwhile, two MMMs could also be compared for $\mathrm{H}_{2} / \mathrm{CH}_{4}$ selectivity, polysulfone-mesoporous silica membrane [9] and hyperbranched hexafluoroisopropylidene/MCM-41 membrane [30]. However, neither of them could achieve high gas separation performance that exceeded the Robeson's upper bound [63], implying the existence of a trade-off relationship.

\section{Permeation model of MMMs containing silica}

In general, there are two permeation models that predict the permeability of MMMs containing silica particles. The first model is applied to predict the permeation of MMMs comprising permeable particles, whereas the other focuses on the prediction of MMMs using impermeable particles. In the case of MMMs incorporated silica, permeable particles refer to porous silica and mesoporous silica such as MCM-41, MCM-48, SBA-15 while impermeable materials refer to nonporous silica like fumed silica. Those models could be applied and modified differently to obtain precise permeation prediction of typical MMMs.

Non-porous silica particles provide the ability to increase the matrix tortuous pattern and decrease the diffusion of larger molecules. Moreover, it could interfere with polymer chain packing, increase the free volume, and finally increase the gas diffusivity. The additional functional group on the particle surface would react with polar gases, thus producing enhanced gas solubility. Using the gas transport mechanism, several models have been applied to predict MMM permeation containing non-porous silica such as the Chiew and Glant model [44], Bruggeman model [6, 44], Higuchi model [59], among others (Table 6).

The Maxwell model is a common prediction tool for MMMs containing non-porous materials dispersed into a polymer matrix as the following Eq. [8]:

$$
\mathrm{P}_{\mathrm{M}}=\mathrm{P}_{\mathrm{C}}\left(\frac{1-\varnothing_{\mathrm{d}}}{1+0.5 \varnothing_{\mathrm{d}}}\right)
$$

where $P_{M}$ is the composite permeability, $P_{C}$ is the polymer matrix permeability (continuous phase) and $\varnothing_{d}$ is the impermeable fillers volume fraction (dispersed phase). Based on this equation, De Angelis and Sarti [64] observed that the permeability of the MMMs formed using fumed silica and several glassy polymers should 


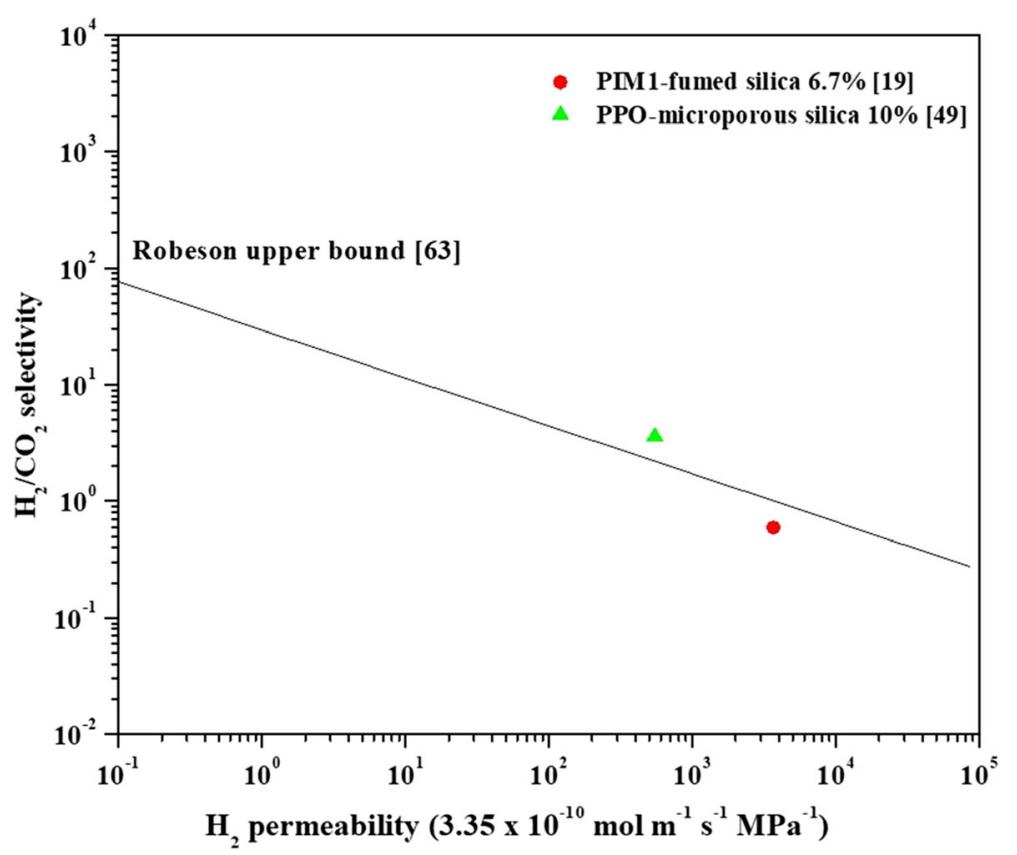

Fig. $15 \mathrm{H}_{2} / \mathrm{CO}_{2}$ selectivity of MMMs compared to Robeson's upper bound [63] (PIM-1: soluble form of polymers of intrinsic microscopy; PPO: polyphenylene oxide)

decrease with the fumed silica load and should remain independent of the particle size. This would contradict the permeability experimental data. This phenomenon certainly occurred because the interactions between the inorganic filler and polymer matrix, and the inorganic filler with penetrant gases were ignored in the Maxwell model. De Angelis and Sarti [64] proposed a free volume model to estimate the variation in the MMM gas transport properties. In this model, the infinite MMM dilution diffusivity, $D_{M}^{0}$ could be estimated using the free volume theory:

$$
D_{M}^{0}=\frac{1}{\tau} \exp \left(A-\frac{B}{F F V_{P, M M}^{0}}\right)
$$

where $\boldsymbol{\tau}$ is the tortuosity, $A$ and $B$ are adjustable parameters, and $F F V_{P, M M}^{0}$ is the fractional free volume of the polymer phase in the membrane state. Moreover, the improvement in diffusivity on MMMs using fumed silica addition only followed one parameter:

$$
\frac{D_{M}^{0}}{D_{P}^{0}}=\frac{1}{\tau} \exp \left[B\left(\frac{1}{F F V_{P}^{0}}-\frac{1}{F F V_{P, M M}^{0}}\right)\right]
$$

The $\beta$ value was estimated by considering different MMMs with increasing fumed silica content and free volume.

$$
\beta=\operatorname{Eexp}\left(-F F F V_{P, M M}^{0}\right)=-F F F V_{P, M M}^{0}+E
$$

where $E$ and $F$ are adjustable parameters. By correlating those equations, the free volume model can be obtained as shown in Table 6. In the free volume model, $\Omega$ is denoted as a unit mass of penetrant or polymer that exists in the MMM. Since $a$ refers to a large penetrant such as nbutane, and $b$ is attributed to a small one such as methane, the $B$ value would be increased with the penetrant size. When $a$ value is larger than the $b$ value, the diffusivity selectivity would be increased and vice versa. However, De Angelis and Sarti [64] emphasized that parameter $B$ is considered a weak function of the penetrant size when the MMMs used very high free volume glassy polymers such as poly(1-trimethylsilyl-1-propyne).

The Maxwell model ignores the presence of interfacial defects between the inorganic filler and polymer matrix and is only available for predicting gas permeation under ideal MMM condition. Hassanajili et al. [44] proposed a model that considered poor organic-inorganic contact as well as the interaction between particles. In this model, four typical phases that exist in MMMs were described including polymer matrix (phase C), dispersed silica particle (phase D), void region (phase I), dispersed silica particle plus void region as pseudo-dispersed phase (phase PS). The Bruggeman model was used to calculate the gas permeability between the MMM polymer and void space that assumed the void region as a continuous phase and the silica particles as the dispersed phase. In 
Table 6 Applied models for predicting permeability of mixed matrix membranes containing non-porous silica

\begin{tabular}{|c|c|c|c|}
\hline Type of polymer & Applied model & Goal & Ref \\
\hline \multirow[t]{4}{*}{ Polyurethane } & $\begin{array}{l}\text { Bruggeman model } \\
\left(\frac{P_{p s}}{P_{l}}\right)^{2 / 3}=\left(1-\varphi_{s}\right)\end{array}$ & $\begin{array}{l}\text { Evaluate the permeability of the gas } \\
\text { between the polymer and the void } \\
\text { space of the nanocomposite. }\end{array}$ & \multirow[t]{4}{*}[53]{} \\
\hline & Modified Knudsen model & \multirow{2}{*}{$\begin{array}{l}\text { Calculate permeability of gas within } \\
\text { the void region }\end{array}$} & \\
\hline & $P=D \times S=9.7 \times 10^{-5} \times \frac{r_{d}+l_{i}}{R T} \sqrt{\frac{T}{M_{A}}} \times$ & & \\
\hline & $\begin{array}{l}\text { Modified Maxwell model } \\
P_{M}=P_{C}\left[\frac{P_{d}+2 P_{C}-2\left(\frac{\mathscr{D}_{D}}{\partial_{S}}\right)\left(P_{C}-P_{d}\right)}{P_{d}+2 P_{C}+\left(\frac{\mathscr{Q}_{D}}{\chi_{S}}\right)\left(P_{C}-P_{d}\right)}\right]\end{array}$ & Evaluate the total gas permeability & \\
\hline \multirow[t]{2}{*}{ Polyurethane } & $\begin{array}{l}\text { Modified Maxwell model } \\
P=D S=\frac{D_{A}}{\gamma}\left(1+\frac{\varphi_{f}}{2}\right)^{-1}\left[S_{A}\left(1-\varphi_{f}\right)+S_{f} \varphi_{f}\right]\end{array}$ & $\begin{array}{l}\text { Calculate gas permeability of } \\
\text { composite membrane }\end{array}$ & \multirow[t]{2}{*}{59} \\
\hline & $\begin{array}{l}\text { Higuchi model } \\
P=P_{A}\left(1-\frac{6 \varphi_{f}}{4+2 \varphi_{f}-K_{H}\left(1-\varphi_{f}\right)}\right)\end{array}$ & $\begin{array}{l}\text { Predict the gas permeability of hybrid } \\
\text { membranes in the presence of } \\
\text { impermeable and spherical fillers like } \\
\text { silica particles. }\end{array}$ & \\
\hline \multirow[t]{4}{*}{$\begin{array}{l}\text { Polyetherurethane, } \\
\text { polyesterurethane }\end{array}$} & $\begin{array}{l}\text { Bruggeman model } \\
\left(\frac{P_{p s}}{P_{j}}\right)^{2 / 3}=\left(1-\varphi_{S}\right)\end{array}$ & $\begin{array}{l}\text { Evaluate the permeability of the gas } \\
\text { between the polymer and the void } \\
\text { space of the nanocomposite. }\end{array}$ & \multirow[t]{4}{*}[44]{} \\
\hline & Modified Knudsen model & \multirow{2}{*}{$\begin{array}{l}\text { Calculate permeability of gas within } \\
\text { the void region }\end{array}$} & \\
\hline & $P=D \times S=9.7 \times 10^{-5} \times \frac{r_{d}+l_{i}}{R T} \sqrt{\frac{T}{M_{A}}} \times$ & & \\
\hline & $\begin{array}{l}\text { Chiew and Glant model } \\
\frac{P_{M}}{P_{C}}=1+3 \beta \varphi_{p s}+K \varphi_{p s}^{2}\end{array}$ & Evaluate the total gas permeability & \\
\hline \multirow[t]{2}{*}{ Glassy polymers } & $\begin{array}{l}\text { Maxwell model } \\
P_{i}=P_{i, P}\left(\frac{1-\varnothing_{F}}{1+0.5 \varnothing_{F}}\right)\end{array}$ & $\begin{array}{l}\text { Estimate the permeability of a } \\
\text { permeable medium filled with a low } \\
\text { content of spherical, impermeable } \\
\text { particles. }\end{array}$ & \multirow[t]{2}{*}[64]{} \\
\hline & $\begin{array}{l}\text { Free volume model } \\
\frac{a_{D, M}}{a_{D, P}}=\exp \left[\left(B_{a}-B_{b}\right)\left(\frac{1}{F F V_{P}^{0}}-\frac{1}{F F V_{P, M M}^{0}}\right)-F_{a}\left(F F V_{P, M M}^{0} \cdot \Omega_{a P, M M}-F F V_{P}^{0} \cdot \Omega_{a P}\right)+E_{a}\left(\Omega_{a P, M M}-\Omega_{a P}\right)\right]\end{array}$ & $\begin{array}{l}\text { Estimate the variation } \\
\text { in diffusivity selectivity due to } \\
\text { the addition of fumed silica }\end{array}$ & \\
\hline $\begin{array}{l}\text { Poly ether block } \\
\text { amide }\end{array}$ & $\begin{array}{l}\text { Van Amerongen and Van Krevelen relations } \\
P_{n}=\frac{D_{0} S_{0}}{\left(\frac{\left(_{E}\right.}{E}\right)^{K}\left(1+0.5 \varnothing_{n}\right)}\left(\frac{1-X_{c, n}}{1-X_{c}}\right)^{2}\left(1-\beta \varnothing_{n}\right) \exp \end{array}$ & $\begin{array}{l}\text { Estimate permeability of the penetrants } \\
\text { through mixed matrix membranes }\end{array}$ & [65] \\
\hline
\end{tabular}

the Bruggeman model, $P_{p s}$ and $P_{l}$ were denoted as gas permeability in the pseudo-dispersed phase and void volume region, respectively, while $\phi_{2}$ was the volume fractions of nano particles in pseudodispersed phase. $\phi_{2}$ could be estimated using the following equation:

$$
\phi_{2}=\frac{\phi_{d}}{\phi_{d}+\phi_{1}}=\left(\frac{r_{d}}{r_{d}+l_{l}}\right)^{3}
$$

where $\phi_{d}, \phi_{1}, r_{d}, l_{l}$ are the volume fractions of silica particles, volume fraction of the interfacial void region, nano particle radius and the void volume layer thickness surrounding the silica particle, respectively. The modified Knudsen model (Table 6) was then used to evaluate gas permeability within the void region. In this model, $d_{g}$ is the molecular gas diameter, $T$, absolute temperature, $M_{A}$, gas molecular weight and $R$, gas constant. Finally, the Chiew and Glant model could be used to evaluate the total gas permeability. The second term in this model (Table 6) implied the interaction between particles and continuous media whereas the third term is attributed to the interaction between particles [44]. In another study, Hassanajili et al. [53] replaced the Chiew and Glant model with a modified Maxwell model to evaluate the total gas permeability.

Semsarzadeh and Ghalei [59] modified Maxwell model to propose a new model (Table 6) according to three main equations. The first equation was arranged based on the correlation between the gas solubility and particle concentration using the following equation:

$$
S=S_{A}\left(1-\phi_{f}\right)+S_{f} \phi_{f}
$$

where $S_{A}$ is attributed to solubility in the polymer matrix, $\phi_{f}$ is the particle volume fraction, and $S_{\mathrm{f}}$ refers to solubility in the particles. The tortuosity factor should then be involved to explain the complete diffusion process: 


$$
D=D_{A} / \tau \gamma
$$

The tortuosity factor, $\tau$, is predicted using the Maxwell theory as shown in Eq. (1). By substituting Eqs. (1), (6), (7), a modified Maxwell model could be obtained (Table 6).

In the porous silica case, no developed model was found to explain the gas transport mechanism through MMMs containing the mesoporous silica. However, several studies tried to investigate the influence of operating temperature on the gas permeability of polymeric membranes such as polyimide [9, 31], polysulfone [9, 35], polysulfone acrylate [32], and polyethersulfone [33] incorporated using mesoporous silica and sulfonated polyether ether ketone with microporous silica [38]. The Arrhenius equation was used to evaluate the relationship between gas permeability and the operating temperature using the permeation activation energy $\left(E_{p}\right)$ as:

$$
\begin{aligned}
& E_{P}=E_{D}+H_{S} \\
& P=P_{0} \exp \left(\frac{E_{P}}{R T}\right)
\end{aligned}
$$

where $E_{D}, H_{S}, P, P_{O}, R$ and $T$ are the diffusion activation energy, sorption heat, gas permeability, preexponential factor, gas constant, and absolute temperature, respectively. Equation (8) implies that the interaction between functional groups on the silica particle surface and the polar penetrant molecules could be able to detract sorption enthalpy for the penetrant, and then enhance the gas permeability.

\section{Challenges and future works in developing MMMs with silica particles as the inorganic filler} Trade-off relationship on MMMs containing silica

Only a few polymeric membranes are incorporated using silica particles that could be able to defeat the opposition relationship, called the trade-off relationship, determined by comparing the permeability and selectivity with the Robeson's upper bound. The trade-off relationship is explained using the following approach. As mentioned previously, there are two major diffusion mechanisms, the Knudsen-diffusion and solution-diffusion mechanism. By incorporating silica particles with typical sized pores, polymer dedensification occurs, then the Knudsen-diffusion mechanism becomes dominant. Non-selective voids also exist when the filler particles do not have good compatibility with the polymer matrix, favouring the same diffusion mechanism. Therefore, an imbalance between these two diffusion mechanisms occurs in the trade-off relationship in MMMs.
The polymer and silica characteristics should be considered to eliminate the trade-off relationship between gas permeability and selectivity. Suzuki and Yamada [61] proposed an acceptable reason for the great performance of MMMs, especially for $\mathrm{CO}_{2} / \mathrm{CH}_{4}$ separation. In fact, the hyperbranched polymer used in MMMs would be able to provide a unique structure surrounding the filler particles, supported by the proper distribution and advantageous linking network for a selective $\mathrm{CO}_{2} / \mathrm{CH}_{4}$ gas separation. The hydrophobic properties of silica with a typical functional group could be utilized to create high chemical affinities for penetrant gases. The adsorption reaction between the silica particles in the polymer matrix plays a role as barrier for penetrant gases to pass through membranes. Additional functional groups are also able to rigidify the non-selective voids around the silica particles and produce a selective path for penetrant gas molecules. Therefore, the new MMMs consisting of hyperbranched polymer and hydrophobic silica with suitable functional groups should be developed in the future to achieve outstanding gas separation performance.

\section{Development of natural silica particle as inorganic filler in MMMs}

Tetraethyl orthosilicate and tetramethyl orthosilicate are known as popular silica precursors for silica synthesis. These chemical precursors provide higher silica purity compared to natural precursors. As mentioned previously, only two studies applied natural silica for fabricating MMMs. Bhattacharya and Mandal [13] developed silica extracted from rice straw using a sol-gel process. They hydrolysed rice straw using ammonium hydroxide to obtain sodium silicate. Sodium silicate was contacted with sulfuric acid to form a transparent silica sol. This silica sol was blended with a polyether-polyamide block co-polymer matrix to fabricate MMMs. Waheed et al. [35] developed a similar method to extract silica from rice husk ash incorporated into a polysulfone matrix for $\mathrm{CO}_{2}$ separation. The extracted silica was functionalized with 4-aminophenazone to improve the resultant membranes. Hence, development of silica from natural resources should be considered as good alternatives for inorganic fillers for preparing MMMs.

In low cost and high purity silica case, many studies have investigated the acid leaching and combustion process to synthesize silica particles from biomass (rice husk). Acid can be used for this treatment including concentrated acid solution (hydrochloric acid and sulfuric acid) and milder acid solution (acetic acid, citric acid, and phosphoric acid). Bakar et al. [66] tried to apply a concentrated acid solution like hydrochloric acid and sulfuric acid combined 
with a combustion process to produce silica from rice husks. The best result from that study is silica with 99.58\% purity, using $0.5 \mathrm{M}$ hydrochloric acid combined with combustion at $600{ }^{\circ} \mathrm{C}$. Note that leaching using strong acid solution could remove metal impurities effectively. Umeda and Kondoh [67] used citric acid to remove metal impurities in rice husks, then combusted it at $800^{\circ} \mathrm{C}$ for $30 \mathrm{~min}$. This treatment successfully produced high purity silica up to $99.77 \%$, due to the effective chelating reaction between $\mathrm{COOH}$ groups and metallic impurities using proper citric acid solution concentration and temperature and stirring time in the solution. Another study, conducted by Carmona et al. [68], proposed three milder acid solutions and combustion to produce high purity rice husk silica. Rice husks and acid solution were submitted to high pressure $196 \mathrm{kPa}$ and temperature $150{ }^{\circ} \mathrm{C}$, then combusted at $650^{\circ} \mathrm{C}$. The result showed that the maximum silica content after this treatment was $99.84 \%$, using phosphoric acid leaching.

\section{Development of MMMs containing silica for acid gas removal}

Instead of the trade-off relationship problem, polymer-silica membranes focused only on separation performances with common gases such as $\mathrm{O}_{2}, \mathrm{CO}_{2}$, $\mathrm{N}_{2}, \mathrm{H}_{2}$, and $\mathrm{CH}_{4}$. As mentioned previously, MMMs containing silica can be considered for $\mathrm{CO}_{2}$ separation in methane and hydrogen purification process due to their $\mathrm{CO}_{2} / \mathrm{CH}_{4}$ and $\mathrm{H}_{2} / \mathrm{CO}_{2}$ selectivity. This study area should be developed as well as creating outstanding MMMs for gas separation and purification. However, MMMs can also play a role in gas pollutant removal processes. A gas removal process is focused on the elimination of acid gases such as $\mathrm{H}_{2} \mathrm{~S}$, and $\mathrm{HCl}$ and alkaline gas $\left(\mathrm{NH}_{3}\right)$ from combustion process. This removal process is strongly dependent on metallic membranes and catalytic processes, which provide high removal efficiency but are costly in installation and require high energy.

Many studies have investigated the ability of various silica particles and their modification to adsorb $\mathrm{H}_{2} \mathrm{~S}$. Tagliabue et al. [69] compared the $\mathrm{H}_{2} \mathrm{~S}$ sorption ability of microporous and (micro) mesoporous silica and silica alumina. Other adsorbents for $\mathrm{H}_{2} \mathrm{~S}$ removal were prepared by synthesizing and modifying the mesoporous molecular silica of SBA-15 with methyl diethyl amine [70], mesoporous silica molecular sieve (MSU-1) supported $\mathrm{ZnO}$ or $\mathrm{CuO}$ [71], amine modified silica xerogel [72], and mesoporous silica supported $\mathrm{Mn}_{2} \mathrm{O}_{3}$ [73]. The potential polymer also provided great ability to treat both $\mathrm{H}_{2} \mathrm{~S}$ and $\mathrm{CO}_{2}$ using polyether urethane urea, polyether block amide, supported ionic liquid membranes, modified cellulose acetate and polybenzimidazole [1]. Therefore, the development of MMMs by combining the sorption ability of modified silica particles and a potential polymer should be considered to remove gas pollutants.

\section{Conclusions}

The following summary and conclusion can be stated from this review:

1. There are three types of silica, classified by their pore size diameter $(\mathrm{nm})$ : non-porous silica, microporous silica $(<2 \mathrm{~nm})$, and mesoporous silica $(2-50$ $\mathrm{nm})$. Those silica particles could be synthesized from many chemical precursors or commercially purchased.

2. Silica particles are incorporated into a polymer matrix using three different methods: solution blending, in-situ sol gel, and in-situ polymerization. The solution blending method is frequently used due to its simplicity.

3. Silica incorporated with a polymer matrix via chemical bonding is due to their original active sites or additional functional group from several coupling agents. This interfacial interaction enhances MMM thermal and mechanical properties.

4. The gas transport mechanism through polymersilica membranes is controlled by the solutiondiffusion mechanism or Knudsen-diffusion mechanism. The adjustment between these two diffusion mechanisms balances the gas permeability and selectivity of the resultant MMMs and disrupts the trade-off relationship.

5. A modified Maxwell theory could be used to explain the gas transport mechanism through MMMs containing non-porous silica. Other models such as the Chiew and Glant model, Bruggeman model and Higuchi model were used to produce a new modified model for describing gas permeation.

6. Generally, MMMs containing silica provide higher gas permeability compared to their pure polymeric membranes due to increasing fraction free volume and the interaction between the active site with penetrant molecules. A trade-off relationship still exists with MMMs containing silica with only a few combination hyperbranched polymer-silica membranes able to achieve high gas separation performance that exceeds the Robeson's upper bound.

7. The development of MMMs for removing gas pollutants should be considered in future works. 


\section{Nomenclature}

\begin{tabular}{|c|c|c|}
\hline Symbol & Variable/Parameter & Unit \\
\hline$\overline{P_{p s},} P_{d}$ & $\begin{array}{l}\text { Permeability of gas in the pseudo-dispersed } \\
\text { phase }\end{array}$ & $\begin{array}{l}\mathrm{molm} \mathrm{m}^{-1} \mathrm{~s}^{-1} \\
\mathrm{MPa}^{-1}\end{array}$ \\
\hline$P_{l}$ & Permeability of gas in void volume region & $\begin{array}{l}\mathrm{molm} \mathrm{m}^{-1} \mathrm{~s}^{-1} \\
\mathrm{MPa}^{-1}\end{array}$ \\
\hline $\begin{array}{l}\varnothing_{S,} \varphi_{s,} \\
\varphi_{p s}\end{array}$ & $\begin{array}{l}\text { Volume fraction of filler in the pseudo- } \\
\text { dispersed phase }\end{array}$ & - \\
\hline$D$ & Diffusion coefficient & $m^{2} s^{-1}$ \\
\hline S & Solubility coefficient & $\begin{array}{l}\mathrm{cm}^{3}(\mathrm{STP}) \\
\mathrm{cm}^{-3} \mathrm{~Pa}^{-1}\end{array}$ \\
\hline$d_{g}$ & Molecular gas diameter & $\mathrm{nm}$ \\
\hline$T$ & Absolute temperature & K \\
\hline$M_{A}$ & Gas molecular weight & $\mathrm{g} \mathrm{mol}^{-1}$ \\
\hline$R$ & Universal gas constant & 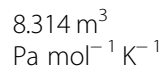 \\
\hline$r_{d}$ & Mean size of filler radius & $\mathrm{nm}$ \\
\hline l, & $\begin{array}{l}\text { Thickness of void space layer of surrounding } \\
\text { filler }\end{array}$ & $\mathrm{mm}$ \\
\hline$P, P_{M}$ & Permeability of mixed matrix membrane & $\begin{array}{l}\mathrm{mol} \mathrm{m} \mathrm{m}^{-1} \mathrm{~s}^{-1} \\
\mathrm{MPa}^{-1}\end{array}$ \\
\hline$P_{A}, P_{C}$ & Permeability of gas in pure polymer matrix & $\begin{array}{l}\mathrm{mol} \mathrm{m} \mathrm{m}^{-1} \mathrm{~s}^{-1} \\
\mathrm{MPa}^{-1}\end{array}$ \\
\hline$\varnothing_{D}$ & $\begin{array}{l}\text { Volume fraction of bulk of nanoparticle in } \\
\text { membrane }\end{array}$ & - \\
\hline$D_{A}$ & Diffusion coefficient in the pure polymer & $m^{2} s^{-1}$ \\
\hline$\gamma$ & Chain immobilization factor & - \\
\hline$\varphi_{f}$ & Volume fraction of particle & - \\
\hline$S_{A}$ & Solubility in the polymer matrix & $\begin{array}{l}\mathrm{cm}^{3}(\mathrm{STP}) \\
\mathrm{cm}^{-3} \mathrm{~Pa}^{-1}\end{array}$ \\
\hline$S_{f}$ & Solubility in the particle & $\begin{array}{l}\mathrm{cm}^{3}(\mathrm{STP}) \\
\mathrm{cm}^{-3} \mathrm{~Pa}^{-1}\end{array}$ \\
\hline$K_{H}$ & Higuchi constant & - \\
\hline$\beta, K$ & $\begin{array}{l}\text { Measure of penetrant permeability difference } \\
\text { between two phases }\end{array}$ & - \\
\hline$P_{i}$ & Permeability of the composite to species $i$ & $\begin{array}{l}\mathrm{mol} \mathrm{m}^{-1} \mathrm{~s}^{-1} \\
\mathrm{MPa}^{-1}\end{array}$ \\
\hline$P_{i, p}$ & Permeability of pure polymer & $\mathrm{MPa}_{\mathrm{MPa}^{-1}}^{-1} \mathrm{~s}^{-1}$ \\
\hline$\Phi_{F}$ & Filler volume fraction & - \\
\hline$a_{D, M}$ & $\begin{array}{l}\text { Diffusion selectivity of mixed matrix } \\
\text { membrane }\end{array}$ & - \\
\hline$a_{D, P}$ & Diffusion selectivity of pure polymer & - \\
\hline$B_{a}$ & Weak function of larger penetrant size & - \\
\hline$B_{b}$ & Weak function of smaller penetrant size & - \\
\hline$F F V_{p}$ & Fractional free volume of pure polymer & - \\
\hline $\begin{array}{l}F F V^{\rho}, \\
M M\end{array}$ & $\begin{array}{l}\text { Fractional free volume of polymer phase in } \\
\text { membrane state }\end{array}$ & - \\
\hline $\begin{array}{l}E_{a \prime} F_{a \prime} \\
K\end{array}$ & Adjustable parameter & - \\
\hline
\end{tabular}

Nomenclature (Continued)

\begin{tabular}{|c|c|c|}
\hline Symbol & Variable/Parameter & Unit \\
\hline$\Omega_{a p}$ & Mass fraction of penetrant gas $a$ & - \\
\hline$\Omega_{a P, M M}$ & $\begin{array}{l}\text { Mass fraction of penetrant gas } a \text { in mixed } \\
\text { matrix polymer }\end{array}$ & - \\
\hline$P_{n}$ & $\begin{array}{l}\text { permeability of penetrants through } \\
\text { nanocomposite membranes }\end{array}$ & $\begin{array}{l}\mathrm{mol} \mathrm{m}^{-1} \mathrm{~s}^{-1} \\
\mathrm{MPa}^{-1}\end{array}$ \\
\hline$S_{0}$ & Pre-exponential solubility coefficient & $\begin{array}{l}\mathrm{cm}^{3}(\mathrm{STP}) \\
\mathrm{cm}^{-3} \mathrm{~Pa}^{-1}\end{array}$ \\
\hline$D_{0}$ & Pre-exponential diffusion coefficient & $m^{2} s^{-1}$ \\
\hline$E_{n}$ & Young's modulus of nanocomposite & $\mathrm{MPa}$ \\
\hline$E$ & Young's modulus of neat membranes & $\mathrm{MPa}$ \\
\hline$\varnothing_{n}$ & Volume fraction of nanoparticle & - \\
\hline$x_{c, n}$ & $\begin{array}{l}\text { Degree of crystallinity of nanocomposite } \\
\text { membranes }\end{array}$ & - \\
\hline$x_{c}$ & Degree of crystallinity of nanoparticle & - \\
\hline$E_{D, n}$ & $\begin{array}{l}\text { Activation energy of diffusion of } \\
\text { nanocomposite membranes }\end{array}$ & $\mathrm{J} \mathrm{mol}^{-1}$ \\
\hline$\Delta H_{c, n}$ & $\begin{array}{l}\text { Enthalpy of condensation of nanocomposite } \\
\text { membranes }\end{array}$ & $\mathrm{J} \mathrm{mol}^{-1}$ \\
\hline$\Delta H_{m, n}$ & $\begin{array}{l}\text { Partial molar enthalpy of mixing of } \\
\text { nanocomposite membranes }\end{array}$ & $\mathrm{J} \mathrm{mol}^{-1}$ \\
\hline
\end{tabular}

\section{Acknowledgments}

The authors would like to thank the Taiwan government of Ministry of Science and Technology (MOST) (MOST-108-2221-E-008-061) for financially supporting this work.

\section{Authors' contributions}

The manuscript draft was interpreted and written by WKS. KY Chiang provided technical support, revised the manuscript, and also supervised the research. All authors read and approved the final manuscript.

\section{Availability of data and materials}

The datasets supporting the conclusions of this article are included within the article.

\section{Competing interests}

The authors declare that they have no competing interests.

Received: 30 January 2019 Accepted: 10 September 2019

Published online: 09 December 2019

\section{References}

1. George G, Bhoria N, AlHallaq S, Abdala A, Mittal V. Polymer membranes for acid gas removal from natural gas. Sep Purif Technol. 2016;158:333-56.

2. Alqaheem $Y$, Alomair A, Vinoba M, Perez A. Polymeric gas-geparation membranes for petroleum refining. Int J Polym Sci. 2017;2017:1-19.

3. Heo J, Lee $\mathrm{B}$, Lim H. Techno-economic analysis for $\mathrm{CO}_{2}$ reforming of a medium-grade landfill gas in a membrane reactor for $\mathrm{H}_{2}$ production. J Clean Prod. 2018;172:2585-93.

4. Han $\mathrm{Y}, \mathrm{Ho}$ WSW. Recent advances in polymeric membranes for $\mathrm{CO}_{2}$ capture. Chinese J Chem Eng. 2018;26:2238-54.

5. Shen Y, Lua AC. Preparation and characterization of mixed matrix membranes based on PVDF and three inorganic fillers (fumed nonporous silica, zeolite 4A and mesoporous MCM-41) for gas separation. Chem Eng J. 2012;192:201-10.

6. Lua AC, Shen Y. Preparation and characterization of polyimide-silica composite membranes and their derived carbon-silica composite membranes for gas separation. Chem Eng J. 2013;220:441-51. 
7. Vinoba M, Bhagiyalakshmi M, Alqaheem Y, Alomair AA, Perez A, Rana MS. Recent progress of fillers in mixed matrix membranes for $\mathrm{CO}_{2}$ separation: a review. Sep Purif Technol. 2017;188:431-50.

8. Aroon MA, Ismail AF, Matsuura T, Montazer-Rahmati MM. Performance studies of mixed matrix membranes for gas separation: a review. Sep Purif Technol. 2010;75:229-42.

9. Zornoza B, Tellez C, Coronas J. Mixed matrix membranes comprising glassy polymers and dispersed mesoporous silica spheres for gas separation. J Membrane Sci. 2011;368:100-9.

10. Bastani D, Esmaeili N, Asadollahi M. Polymeric mixed matrix membranes containing zeolites as a filler for gas separation applications: a review. J Ind Eng Chem. 2013;19:375-93.

11. Bento A, Lourenco JP, Fernandes A, Ribeiro MR, Arranz-Andres J, Lorenzo V, et al. Gas permeability properties of decorated MCM-41/polyethylene hybrids prepared by in-situ polymerization. J Membrane Sci. 2012;415-6:702-11.

12. Azizi N, Mohammadi T, Behbahani RM. Comparison of permeability performance of PEBAX-1074/TiO $2, \mathrm{PEBAX}-1074 / \mathrm{SiO}_{2}$ and PEBAX-1074/ $/ \mathrm{Al}_{2} \mathrm{O}_{3}$ nanocomposite membranes for $\mathrm{CO}_{2} / \mathrm{CH}_{4}$ separation. Chem Eng Res and Des. 2017;117:177-89.

13. Bhattacharya M, Mandal MK. Synthesis of rice straw extracted nano-silicacomposite membrane for $\mathrm{CO}_{2}$ separation. J Clean Prod. 2018;186:241-52.

14. Ghadimi A, Mohammadi T, Kasiri N. Gas permeation, sorption and diffusion through $\mathrm{PEBA} / \mathrm{SiO}_{2}$ nanocomposite membranes (chemical surface modification of nanoparticles). Int J Hydrogen Energ. 2015;40:9723-32.

15. Lovineh SG, Asghari M, Khanbabaei G. $\mathrm{CO}_{2}$ permeation through poly(amide6-b-ethylene oxide)-nanosilica membranes. Appl Surf Sci. 2014;318:176-9.

16. Rafiq S, Man Z, Maulud A, Muhammad N, Maitra S. Separation of $\mathrm{CO}_{2}$ from $\mathrm{CH}_{4}$ using polysulfone/ polyimide silica nanocomposite membranes. Sep Purif Technol. 2012;90:162-72.

17. Sadeghi M, Semsarzadeh MA, Moadel H. Enhancement of the gas separation properties of polybenzimidazole (PBI) membrane by incorporation of silica nano particles. J Membrane Sci. 2009;331:21-30.

18. Aghaei Z, Naji L, Asl VH, Khanbabaei G, Dezhagah F. The influence of fumed silica content and particle size in poly (amide 6-b-ethylene oxide) mixed matrix membranes for gas separation. Sep Purif Technol. 2018;199:47-56.

19. Ahn J, Chung WJ, Pinnau I, Song J, Du N, Robertson GP, et al. Gas transport behavior of mixed-matrix membranes composed of silica nanoparticles in a polymer of intrinsic microporosity (PIM-1). J Membrane Sci. 2010;346:280-7.

20. Isanejad M, Mohammadi T. Effect of amine modification on morphology and performance of poly (ether-block-amide)/fumed silica nanocomposite membranes for $\mathrm{CO}_{2} / \mathrm{CH}_{4}$ separation. Mater Chem Phys. 2018;205:303-14.

21. Khanbabaei G, Vasheghani-Farahani E, Rahmatpour A. Pure and mixed gas $\mathrm{CH}_{4}$ and $\mathrm{n}-\mathrm{C}_{4} \mathrm{H}_{10}$ permeation in PDMS-fumed silica nanocomposite membranes. Chem Eng J. 2012;191:369-77.

22. Mahdavi $\mathrm{H}$, Moradi-Garakani F. Effect of mixed matrix membranes comprising a novel trinuclear zinc MOF, fumed silica nanoparticles and PES on $\mathrm{CO}_{2} / \mathrm{CH}_{4}$ separation. Chem Eng Res Des. 2017;125:156-65.

23. Ogbole EO, Lou J, llias S, Desmane V. Influence of surface-treated $\mathrm{SiO}_{2}$ on the transport behavior of $\mathrm{O}_{2}$ and $\mathrm{N}_{2}$ through polydimethylsiloxane nanocomposite membrane. Sep Purif Technol. 2017;175:358-64

24. Shen Y, Lua AC. Structural and transport properties of BTDA-TDI/MDI copolyimide (P84)-silica nanocomposite membranes for gas separation. Chem Eng J. 2012;188:199-209.

25. Wahab MFA, Ismail AF, Shilton SJ. Studies on gas permeation performance of asymmetric polysulfone hollow fiber mixed matrix membranes using nanosized fumed silica as fillers. Sep Purif Technol. 2012:86:41-8.

26. Kwon Y, Im H, Kim J. Effect of PMMA-graft-silica nanoparticles on the gas permeation properties of hexafluoroisopropylidene-based polyimide membranes. Sep Purif Technol. 2011;78:281-9.

27. Suzuki T, Yamada Y. Effect of thermal treatment on gas transport properties of hyperbranched polyimide-silica hybrid membranes. J Membrane Sci. 2012;417:193-200.

28. Zhang H, Goeppert A, Olah GA, Prakash GKS. Remarkable effect of moisture on the $\mathrm{CO}_{2}$ adsorption of nano-silica supported linear and branched polyethylenimine. J CO2 Util. 2017;19:91-9.

29. Xing R, Ho WSW. Crosslinked polyvinylalcohol-polysiloxane/fumed silica mixed matrix membranes containing amines for $\mathrm{CO}_{2} / \mathrm{H}_{2}$ separation. J Membrane Sci. 2011;367:91-102.

30. Galve A, Sieffert D, Staudt C, Ferrando M, Guell C, Téllez C, et al. Combination of ordered mesoporous silica MCM-41 and layered titanosilicate JDF-L1 fillers for 6FDA-based copolyimide mixed matrix membranes. J Membrane Sci. 2013:431:163-70.

31. Khan AL, Klaysom C, Gahlaut A, Khan AU, Vankelecom IFJ. Mixed matrix membranes comprising of Matrimid and $-\mathrm{SO}_{3} \mathrm{H}$ functionalized mesoporous MCM-41 for gas separation. J Membrane Sci. 2013;447:73-9.

32. Khan AL, Klaysom C, Gahlaut A, Vankelecom IFJ. Polysulfone acrylate membranes containing functionalized mesoporous MCM-41 for $\mathrm{CO}_{2}$ separation. J Membrane Sci. 2013;436:145-53.

33. Laghaei M, Sadeghi M, Ghalei B, Shahrooz M. The role of compatibility between polymeric matrix and silane coupling agents on the performance of mixed matrix membranes: polyethersulfone/MCM-41. J Membrane Sci. 2016;513:20-32.

34. Park S, Bang J, Choi J, Lee SH, Lee JH, Lee JS. 3-dimensionally disordered mesoporous silica (DMS)-containing mixed matrix membranes for $\mathrm{CO}_{2}$ and non- $\mathrm{CO}_{2}$ greenhouse gas separations. Sep Purif Technol. 2014;136:286-95.

35. Waheed N, Mushtaq A, Tabassum S, Gilani MA, Ilyas A, Ashraf F, et al. Mixed matrix membranes based on polysulfone and rice husk extracted silica for $\mathrm{CO}_{2}$ separation. Sep Purif Technol. 2016;170:122-9.

36. Wu H, Li XQ, Li YF, Wang SF, Guo RL, Jiang ZY, et al. Facilitated transport mixed matrix membranes incorporated with amine functionalized MCM-41 for enhanced gas separation properties. J Membrane Sci. 2014;465:78-90.

37. Lanc M, Friess K, Hynek V, Sysel P, Celisova M, Stepanek F, et al. Permeation and sorption of gases in mixed matrix membranes based on hyperbranched polyimides and hollow silica microspheres. Procedia Engineer. 2012;44:815-6.

38. Xin $Q P$, Zhang $Y$, Shi $Y$, Ye $H$, Lin $L G$, Ding $X L$, et al. Tuning the performance of $\mathrm{CO}_{2}$ separation membranes by incorporating multifunctional modified silica microspheres into polymer matrix. J Membrane Sci. 2016;514:73-85.

39. Ahmad NA, Noh ANM, Leo CP, Ahmad AL. $\mathrm{CO}_{2}$ removal using membrane gas absorption with PVDF membrane incorporated with POSS and SAPO-34 zeolite. Chem Eng Res Des. 2017;118:238-47.

40. Guerrero G, Hagg MB, Kignelman G, Simon C, Peters T, Rival N, et al. Investigation of amino and amidino functionalized polyhedral oligomeric SilSesquioxanes (POSS ${ }^{\oplus}$ ) nanoparticles in PVA-based hybrid membranes for $\mathrm{CO}_{2} / \mathrm{N}_{2}$ separation. J Membrane Sci. 2017;544:161-73.

41. Guerrero G, Venturi D, Peters T, Rival N, Denonville C, Simon C, et al. Influence of functionalized nanoparticles on the $\mathrm{CO}_{2} / \mathrm{N}_{2}$ separation properties of PVAbased gas separation membranes. Enrgy Proced. 2017;114:627-35.

42. Kinoshita Y, Wakimoto K, Gibbons AH, Isfahani AP, Kusuda H, Sivaniah E, et al. Enhanced PIM-1 membrane gas separation selectivity through efficient dispersion of functionalized POSS fillers. J Membrane Sci. 2017;539:178-86.

43. Lanc M, Sysel P, Soltys M, Stepanek F, Fónod K, Klepic M, et al. Synthesis, preparation and characterization of novel hyperbranched 6FDA-TTM based polyimide membranes for effective $\mathrm{CO}_{2}$ separation: effect of embedded mesoporous silica particles and siloxane linkages. Polymer. 2018;144:33-42.

44. Hassanajili S, Masoudi E, Karimi G, Khademi M. Mixed matrix membranes based on polyetherurethane and polyesterurethane containing silica nanoparticles for separation of $\mathrm{CO}_{2} / \mathrm{CH}_{4}$ gases. Sep Purif Technol. 2013;116:1-12.

45. Silaghi MC, Chizallet C, Raybaud P. Challenges on molecular aspects of dealumination and desilication of zeolites. Micropor and Mesopor Mat. 2014;191:82-96.

46. Amedi HR, Aghajani M. Gas separation in mixed matrix membranes based on polyurethane containing $\mathrm{SiO}_{2}, \mathrm{ZSM}-5$, and ZIF-8 nanoparticles. J Nat Gas Sci Eng. 2016;35:695-702.

47. Khdary NH, Abdelsalam ME. Polymer-silica nanocomposite membranes for $\mathrm{CO}_{2}$ capturing. Arab J of Chem. 2017; In press.

48. Tseng HH, Chuang HW, Zhuang GL, Lai WH, Wey MY. Structure-controlled mesoporous SBA-15-derived mixed matrix membranes for $\mathrm{H}_{2}$ purification and $\mathrm{CO}_{2}$ capture. Int J Hydrogen Energ. 2017;42:11379-91.

49. Zhuang GL, Tseng HH, Wey MY. Preparation of PPO-silica mixed matrix membranes by in-situ sol-gel method for $\mathrm{H}_{2} / \mathrm{CO}_{2}$ separation. Int J Hydrogen Energ. 2014;39:17178-90.

50. Sadeghi M, Mehdi Talakesh M, Ghalei B, Shafiei M. Preparation, characterization and gas permeation properties of a polycaprolactone based polyurethane-silica nanocomposite membrane. J Membrane Sci. 2013:427:21-9.

51. Sadeghi M, Semsarzadeh MA, Barikani M, Pourafshari CM. Gas separation properties of polyether-based polyurethane-silica nanocomposite membranes. J Membrane Sci. 2011;376:188-95.

52. Hasebe $\mathrm{S}$, Aoyama $\mathrm{S}$, Tanaka M, Kawakami $\mathrm{H} . \mathrm{CO}_{2}$ separation of polymer membranes containing silica nanoparticles with gas permeable nano-space. J Membrane Sci. 2017;536:148-55. 
53. Hassanajili S, Khademi M, Keshavarz P. Influence of various types of silica nanoparticles on permeation properties of polyurethane/silica mixed matrix membranes. J Membrane Sci. 2014;453:369-83.

54. Goh PS, Ismail AF, Sanip SM, Ng BC, Aziz M. Recent advances of inorganic fillers in mixed matrix membrane for gas separation. Sep Purif Technol. 2011;81:243-64.

55. Valero M, Zornoza B, Tellez C, Coronas J. Mixed matrix membranes for gas separation by combination of silica MCM-41 and MOF $\mathrm{NH}_{2}-\mathrm{MIL}-53$ (Al) in glassy polymers. Micropor and Mesopor Mat. 2014;192:23-8.

56. Lee DW, Yoo BR. Advanced silica/polymer composites: materials and applications. J Ind Eng Chem. 2016;38:1-12.

57. Salim W, Ho WSW. Hydrogen purification with $\mathrm{CO}_{2}$-selective facilitated transport membranes. Curr Opin Chem Eng. 2018;21:96-102.

58. Ahmadizadegan $\mathrm{H}$, Esmaielzadeh $\mathrm{S}$. Novel polyester $/ \mathrm{SiO}_{2}$ nanocomposite membranes: synthesis, properties and morphological studies. Solid State Sci. 2018:80:81-91.

59. Semsarzadeh MA, Ghalei B. Preparation, characterization and gas permeation properties of polyurethane-silica/polyvinyl alcohol mixed matrix membranes. J Membrane Sci. 2013;432:115-25.

60. Sekizkardes AK, Zhou X, Nulwala HB, Hopkinson D, Venna SR. Ionic crosslinked polyether and silica gel mixed matrix membranes for $\mathrm{CO}_{2}$ separation from flue gas. Sep Purif Technol. 2018;191:301-6.

61. Suzuki T, Yamada Y. Synthesis and gas transport properties of novel hyperbranched polyimide-silica hybrid membranes. J Appl Polym Sci. 2013; 127:316-22.

62. Golzar K, Amjad-Iranagh S, Amani M, Modarress H. Molecular simulation study of penetrant gas transport properties into the pure and nanosized silica particles filled polysulfone membranes. J Membrane Sci. 2014;451:117-34.

63. Robeson LM. The upper bound revisited. J Membrane Sci. 2008;320:390-400

64. De Angelis MG, Sarti GC. Gas sorption and permeation in mixed matrix membranes based on glassy polymers and silica nanoparticles. Curr Opin Chem Eng. 2012;1:148-55.

65. Ghadimi A, Mohammadi T, Kasiri N. Mathematical modeling of the gas transport through PEBAX/(nonporous silica) nanocomposite membranes: development based on Van Amerongen and Van Krevelen relations. Sep Purif Technol. 2016;170:280-93.

66. Bakar RA, Yahya R, Gan SN. Production of high purity amorphous silica from rice husk. Procedia Chem. 2016:19:189-95.

67. Umeda J, Kondoh K. High-purification of amorphous silica originated from rice husks by combination of polysaccharide hydrolysis and metallic impurities removal. Ind Crop Prod. 2010;32:539-44.

68. Carmona VB, Oliveira RM, Silva WTL, Mattoso LHC, Marconcini JM. Nanosilica from rice husk: extraction and characterization. Ind Crop Prod. 2013;43:291-6.

69. Tagliabue M, Bellussi G, Broccia P, Carati A, Millini R, Pollesel P, et al. High pressure hydrogen sulphide adsorption on silica-aluminas. Chem Eng J. 2012;210:398-403.

70. Xue QM, Liu YS. Removal of minor concentration of $\mathrm{H}_{2} \mathrm{~S}$ on MDEA-modified SBA-15 for gas purification. J Ind Eng Chem. 2012;18:169-73.

71. Montes D, Tocuyo E, Gonzalez E, Rodri uez D, Solano R, Atencio R, et al. Reactive $\mathrm{H}_{2} \mathrm{~S}$ chemisorption on mesoporous silica molecular sievesupported CuO or ZnO. Micropor Mesopor Mat. 2013:168:111-20.

72. Jaiboon V, Yoosuk B, Prasassarakich P. Amine modified silica xerogel for $\mathrm{H}_{2} \mathrm{~S}$ removal at low temperature. Fuel Process Technol. 2014;128:276-82.

73. Zhang ZF, Liu BS, Wang F, Wang WS, Xia C, Zheng S, Amin R. Hydrogen sulfide removal from hot coal gas by various mesoporous silica supported $\mathrm{Mn}_{2} \mathrm{O}_{3}$ sorbents. Appl Surf Sci. 2014;313:961-9.

\section{Publisher's Note}

Springer Nature remains neutral with regard to jurisdictional claims in published maps and institutional affiliations.

Ready to submit your research? Choose BMC and benefit from:

- fast, convenient online submission

- thorough peer review by experienced researchers in your field

- rapid publication on acceptance

- support for research data, including large and complex data types

- gold Open Access which fosters wider collaboration and increased citations

- maximum visibility for your research: over $100 \mathrm{M}$ website views per year

At $\mathrm{BMC}$, research is always in progress.

Learn more biomedcentral.com/submissions 